\title{
Design and Optimization of Slotted Block Horn Utilized in Ultrasonic Insertion Process Through Rsm-fea-ga Integration Technique
}

Anand Kumarasamy ( $\sim$ mechanand@gmail.com )

PSG COLLEGE OF TECHNOLOGY

Elangovan Sooriyamoorthy

\section{Research Article}

Keywords: Ultrasonic insertion, Slotted block horn, FEA, RSM, GA, Temperature measurement.

Posted Date: May 18th, 2021

DOI: https://doi.org/10.21203/rs.3.rs-260954/v1

License: (c) (i) This work is licensed under a Creative Commons Attribution 4.0 International License.

Read Full License 


\title{
Design and optimization of slotted block horn utilized in ultrasonic insertion process through RSM-FEA-GA integration technique
}

\author{
Anand Kumarasamy*, Elangovan Sooriyamoorthy \\ Department of Production Engineering, PSG College of Technology, Coimbatore, 641 004, Tamil Nadu, India \\ E-mail: mechanand@gmail.com ph: +91-9791333205
}

Abstract: This paper investigates design and optimization of slotted block horn used in ultrasonic insertion process by integrating response surface methodology (RSM), finite element analysis (FEA) and genetic algorithm (GA). Performance and reliability of block horn depend on the uniformity of displacement amplitude developed at the output face of horn. Amplitude uniformity of horn can be improved by optimizing the design of block horn. Modal and harmonic analyses are carried out as per design matrix obtained from RSM, and then non-linear model for displacement amplitude is developed. Design optimization of block horn is performed by coupling the non-linear model with GA as fitness function. Thermal analysis is carried out to validate optimized dimensions of block horn theoretically by predicting the temperature at joint. Slotted block horn is fabricated with optimum geometry using Aluminium alloy (AA6351) and the design is validated experimentally by measuring the temperature at joint using thermocouple and Data Acquisition System (DAQ). Results of this study show that the temperature predicted from thermal analysis correlates well with temperature measured from experiments and the design of slotted block horn is validated.

Keywords: Ultrasonic insertion, Slotted block horn, FEA, RSM, GA, Temperature measurement.

\section{Introduction}

Increasing the usage of plastic components in wide array of industries necessitated a suitable method for fastening the plastic component with metallic part. When the plastic parts are fastened by self-tapping screws or bolts, it may get damaged due to plastic creep and stripped threads. In these circumstances, a technique is needed which has to improve joint performance (Pull-out strength and Stripping torque), without degrading them. Many techniques are available to fasten the plastic component with metal insert such as over moulding (pre-moulding), cold pressing and thermal insertion. Metal inserts can be pre-moulded directly into the plastic component. This is achieved by placing metal insert on the guide pins which is located in the mould cavity. Guide pins hold the metal inserts in the appropriate places and molten plastic is injected into the mould cavity to flow around the external features of metal insert. Inserts will be locked in the respective places once the polymer freezes evenly around the metal insert. The main drawbacks of pre-moulding process are more stress concentration due to different cooling rate of metal insert and plastic component. Also, cycle time of this process increases due to positioning the metal insert at appropriate places in the mould cavity using guide pins. In some cases, metal inserts may be moved away from the guide pins if it is not located properly and expensive die may get damaged. Sometimes, while moulding molten plastic material gets trapped into the internal threads of metal insert and this phenomenon requires retapping after completion of moulding process.

Cold pressing is another method for encapsulating metal inserts into the plastic components. This process could not provide high torsional resistance and pull-out strength for the joint, because inserts are being reamed into 
solid state plastic component or enough volume of plastic material may not be melted and flow around the external features of metal insert. This can damage the inserts and plastic parts as well.

In thermal insertion process, insertion press or ram with heated tip is used to press the metal insert into plastic component. Temperature of metal insert and plastic material is raised by heated tip of the press/ram through thermal conduction and then metal insert is pushed into the heated thermoplastic component. After encapsulation of metal insert, the heated tip of press/ram is retracted and plastics are allowed to solidify around the metal insert. Since the entire metal insert is heated, it will take more time to cool after installation and a small amount of back-out of the insert may occur. So, ultrasonic insertion can be used as alternate for pre- moulding, cold pressing and thermal insertion processes. Ultrasonic insertion is most preferred process compared with other insertion processes because of shorter cycle time, minimal induced stress and automation possibilities for mass production.

In ultrasonic insertion process, an internally threaded metal insert is encapsulated into thermoplastic part through remelting it. In this method, a metal insert is placed on pre-moulded or drilled hole which is smaller in diameter than metal insert. The ultrasonic vibration generated from horn presses and transfers the ultrasonic energy to the metal insert. Frictional force induced at the interface of metal insert and thermoplastic component generates heat energy which softens the thermoplastic material and sufficient volume of plastic displaced into external features of metal insert to produce joint. The ultrasonic insertion process is pictorially represented in Fig. 1. Metal inserts are the mechanical fasteners which are used to assemble and disassemble the components with other mating parts. Inserts provide resistance to both axial and angular movement by endow with knurls, grooves and undercuts on the external surface of the insert.

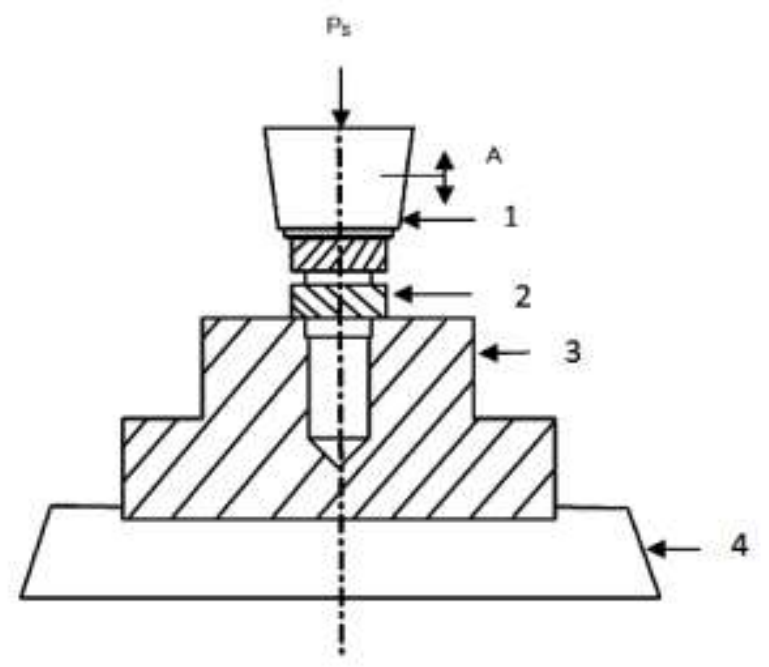

\section{Ultrasonic horn 2. Metal insert 3. Thermoplastic part 4. Anvil \\ A - Amplitude of horn vibrations $\mathrm{P}_{\mathrm{S}}-$ Static pressure force}

Fig. 1 Schematic representation of ultrasonic insertion process

The functional requirements of ultrasonically fastened joint are decided by the specifications metal insert, mounting hole and design of horn. Poor insertion quality is the major problem concerned with ultrasonic insertion process. Improper insertion affects the function of the product and leads to damage. These problems arise because of the improper design of horn. In general, only one insertion can be done at a time using cylindrical type of solid horn. For increasing the rate of production, block horns may be used for multiple insertions. But, the issues with block 
horn are more in weight and uneven transmission of amplitude of vibrations which affects the performance of ultrasonically fastened joint. The longitudinal slots can reduce the weight of the block horn and the uniformity of displacement amplitude can be improved by optimizing the slot dimensions, number of slots and location of the slots. Research papers relevant to computational modelling of solid and slotted block horn using finite element method and statistical analysis were reviewed which are useful for giving background of this study.

Roopa Rani et al. [1] studied the far field welding of semi crystalline polymer using finite element analysis. Temperature distribution at joint was modeled for various lengths of thermoplastic specimen to predict the temperature spikes, which can be related to the performance of the joints achieved. The results reveal that amplitude selection plays a crucial part in welding of semi-crystalline polymers in far field region and more amplitude was preferred for obtaining higher interface temperatures for a given length of the specimen.

Cardoni and Lucas [2] investigated the performance of ultrasonic block horns using finite element analysis. Uniform amplitude of vibration at the working surface was needed to improve the performance of block horn. The slot geometry in block horn design was positioned to maximize the amplitude of vibration using finite element analysis. Vibration frequency of the block horn was measured experimentally using 3D doppler vibrometer. Further, the results from finite element analysis were validated with experimental results.

Graham et al. [3] presented the results of modal analysis of an ultrasonic block horns by Electronic Speckle Pattern Interferometry (ESPI). The block horn was modeled and analyzed using finite element method. Frequency response function data was obtained from ESPI data by monitoring the electrical signal. The modal parameters were extracted from the ESPI data using modal analysis software. The authors concluded that results from the modal analysis were correlated well with finite element analysis results.

Lucas and Smith [4] redesigned ultrasonic block horns for improving the performance of horn. Modal analysis was performed on block horn using finite element analysis. Two laser-based vibration measurement techniques namely laser doppler velocimetry and electronic speckle pattern interferometry was used to measure natural frequency of horns experimentally. Then the experimental data were compared with finite element analysis results to improve the design of block horn.

Sun-Rak Kim et al. [5] studied the influence of groove and slot dimensions for designing spool and bar horns to achieve high amplitude uniformity using Design of Experiments (DOE). Natural frequency and displacement amplitude of horns were analyzed using finite element method. The FEA results shows that slot width and groove depth have significant effect on amplitude uniformity. Spool and bar horns were fabricated for optimized dimensions. Displacement amplitude for both horns was measured using a laser doppler vibrometer and result was good in agreement with predicted results.

Roopa Rani and Rudramoorthy [6] developed computational models for various profile of solid horn used in ultrasonic plastic welding to determine the dynamic characteristics. Modal, harmonic and thermal analyses were carried out for various horn profiles using finite element analysis and the temperature at joint was predicted. The temperature at joint interface of ABS test specimen was measured experimentally using thermocouple and data acquisition system and that was compared with predicted results. The results show that temperature at joint was higher for Bezier horn which results in higher weld strength compared to other profiles.

Roopa Rani et al. [7] studied the thermo-elastic heating of ultrasonic plastic welding for different materials. Horns were fabricated with different materials like aluminium, titanium, mild steel and stainless steel. The 
temperatures at different nodes of horn were predicted theoretically and compared with experimental results. The results show that titanium horn had lowest temperature at the critical region and it vibrates at amplitude of $77 \mu \mathrm{m}$ without failure under cyclic load.

Dipin kumar et al. [8] designed and analyzed slotted horn for ultrasonic plastic welding through FEA, factorial design and genetic algorithm. Modal and harmonic analyses were performed as per full factorial design. Second order mathematical model for amplitude of vibration was developed and the same was coupled with GA to optimize the design of slotted block horn. From their results it was observed that optimized block horn vibrates in longitudinal mode with uniform displacement amplitude.

Guangchao Han et al. [9] developed a new type of porous block sonotrode for an ultrasonic assisted micro plastic forming using finite element analysis. Modal and harmonic analyses were performed for porous sonotrode to optimize the locations of holes. Results of their study show that porous sonotrode performs better than regular sonotrode without any structural and load change. FEA results are validated by conducting experiments.

Kumar et al. [10] have analyzed the dynamic performance of a complex ultrasonic horn utilized in friction stir welding process through finite element method. Modal and harmonic analyses were performed for simple and complex profiled horns to determine the dynamic properties. From the FEA results, it was understood that vonMisses stress induced in the horn well within the limit of yield strength of horn material which ensures that the design was safe. Also, it was observed that FEA results were validated by monitoring the frequency and amplitude of vibration through laser vibrometer.

Shimaalsadat et al. [11] studied the influence of interface temperature in ultrasonic joining of aluminium strands using numerical simulations and experimental measurements. Coupled thermo - mechanical finite element analysis was performed to predict the interface temperature in aluminium strands bundle. Totally 9 experiments were conducted for different combination of ultrasonic welding parameters such as pressure, amplitude of vibration and weld time. From the results of numerical simulations and experiments, it was noted that welding pressure on the strands improves the welding efficiency but under extended welding pressure, strands may undergo strong plastic deformation and better strength was not achieved.

Li et al. [12] developed a three-dimensional finite element model to investigate the effect of resistance heat on ultrasonic welding of $\mathrm{Cu}-\mathrm{Al}$ joint. The simulated result shows that resistance heat played an important role in hybrid welding to increase the interface temperature, accelerate the penetration of teeth and enhance the plastic deformation in the workpieces. Finite element model results were verified with experimental results and they were in good agreement.

Shuyu Lin et al. [13] studied and proposed longitudinal step type ultrasonic horn with adjustable performance. Influence of the location of piezoelectric material and electric impedance on resonance frequency and amplitude of vibration were studied. Results of their study show that both resonance frequency and amplitude of vibration were increased when piezoelectric material located on larger end of horn. Also, the resonance frequency was increased and amplitude of vibration was decreased when the piezoelectric material was on the smaller end of horn. The proposed method suggests that horn performance can be optimized by adjusting the location of piezoelectric material and electric impedance.

Dongkyun Lee and Wayne Cai [14] carried out numerical simulations to investigate the effect of horn knurl designs on ultrasonic weld quality using finite element analysis. 2D welding simulations were performed to study the maximum principal plastic strain along with abbreviated and surrogated simulations to examine the weld quality. 
The simulation results were experimentally validated by measuring the surface profile using laser scanning microscope. The authors concluded that results of their study provide guidelines to design the horn knurl geometry for improving weld quality.

Muhammad Bilal et al. [15] designed longitudinal torsional mode ultrasonic welding horn using FEA coupled with artificial neural network approach. Composite mode horn with slanting grooves was designed for ultrasonic welding. The modal and harmonic analyses were performed to determine effect of slanting angle of groove depth, length, width and distance on the torsionality and resonance frequency of welding horn using finite element analysis. The results obtained from simulations were used to train multi-layer neural network and the trained network can be used to assist the designing of horn.

Ziad shakeup et al. [16] designed and simulated the ultrasonic block horn with slots using finite element method. Various configurations of slotted block horn were created and simulated to optimize the slot position which yields maximum amplitude of vibration. The FEA results of their study showed that block horn with two slots improves the amplitude of vibration. The FEA results were validated by conducting experiments with the help of 3D laser doppler vibrometer.

Elangovan et al. [17] optimized ultrasonic metal welding parameters using Taguchi DOE and studied the temperature and stress distribution at the joint of Al-Al using finite element analysis. From the results of their study, it is understood that increasing weld time weld strength and stress as well. The temperature at weld joint predicted from FEA were good in agreement with temperature measured from experiments.

Elangovan et al. [18] carried out a study on parameter optimization using response surface methodology and genetic algorithm in ultrasonic metal welding. The results show that optimized welding conditions obtained from genetic algorithm were good in agreement with experimental results. So, response surface methodology and genetic algorithm can be adopted for optimizing input variable to improve the performance of output variables.

From the abovementioned literature review, it is understood that the existing studies abortive to reveal a technique for optimizing the design of slotted block horn used in ultrasonic insertion process. Besides, few researchers have attempted to optimize the design of block horn for improving the performance of horn. But the results of their study could not relate performance of block horn with desired outcomes relevant processes where the optimized block was utilized. It was observed that various profiles of solid horns were investigated and optimum profile was validated by conducting experiments. Also, it was noted that no research was attempted to improve the performance of ultrasonic insertion process by optimizing the design of slotted block horn. To deal with these shortcomings, design and optimization of slotted block horn was attempted in this study for improving the performance of ultrasonically fastened joint using response surface methodology, finite element analysis and genetic algorithm.

\section{Methodology}

Methodology adopted for design and optimization of slotted block horn used for multiple insertions is shown in Fig. 2. Industrial component with multiple inserts is identified, designed and fabricated as per standards to optimize the design of slotted block horn. Ranges for each design variable (slot dimension, number of slots and location of the slot) is fixed by conducting preliminary analysis (modal). Non-linear model for displacement amplitude is developed using modal and harmonic analysis as per central composite design obtained from RSM. Non-linear model is used as fitness function in GA to obtain the optimized geometries of block horn. Thermal analysis is carried out on thermoplastic component for optimum design of slotted block horn to predict the 
temperature at joint. Design of slotted block horn is validated by measuring the temperature at joint interface using thermocouples and Data Acquisition System (DAQ). 


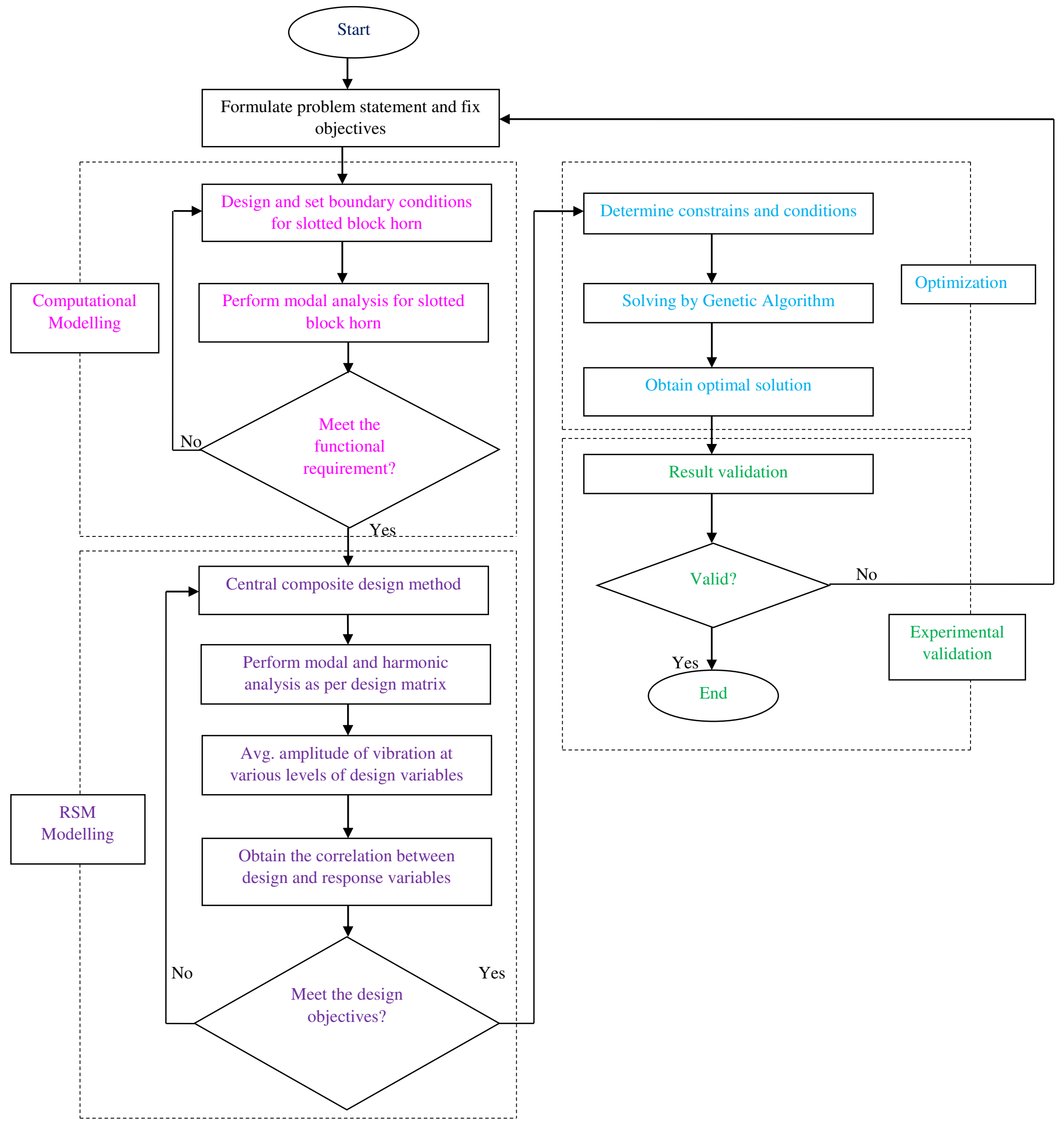

Fig. 2 Methodology for design and optimization of slotted block horn 


\section{Computational modelling of slotted block horn}

\section{1 Preparation of ABS thermoplastic component and metal insert}

Thermoplastic component chosen for multiple insertions is back-end cover of the electrical switch box. The thermoplastic mounting hole, in which brass insert to be encapsulated should be prepared in such a way that sufficient quantity of softened thermoplastic material to be moved around the external features of insert and lock it in place to ensure the functional requirements of the joint. Optimum insertion performance is achieved when the outside diameter (boss diameter) of thermoplastic mounting hole is twice than diameter of brass insert. The diameter of thermoplastic mounting hole is usually smaller than $(0.38 \mathrm{~mm}-0.51 \mathrm{~mm})$ outside diameter of brass insert. The depth of mounting hole should be slightly greater than height of brass insert to prevent "back out" of metal insert [20]. The specifications of back-end cover of the electrical switch box are shown in Fig. 3.

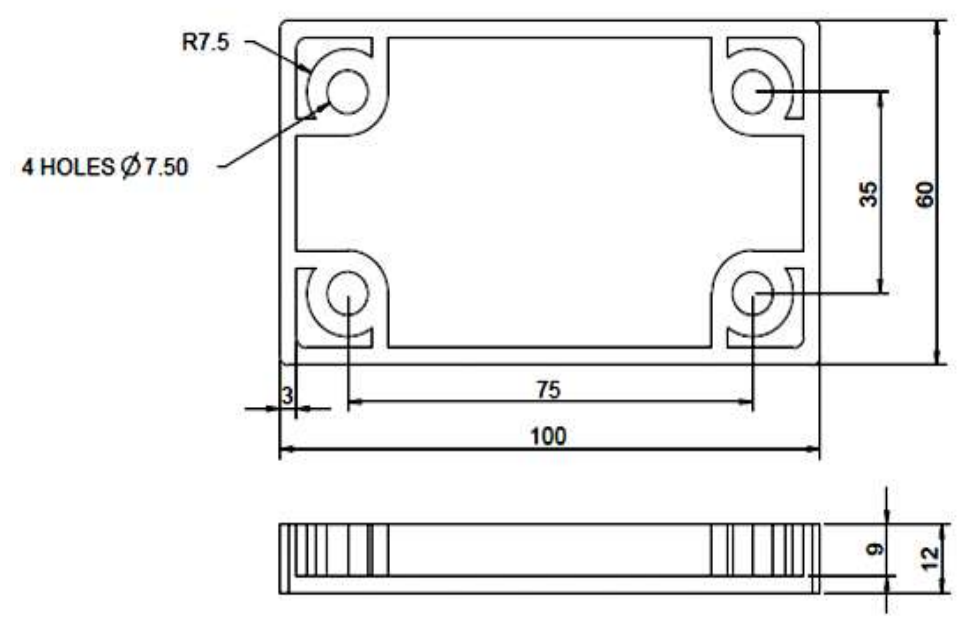

Fig. 3 Back-end cover of the electrical switch box with dimensions

The designed thermoplastic component is fabricated with Acrylonitrile Butadiene Styrene (ABS) material using plastic injection moulding machine. Standard brass inserts are selected for multiple insertions. The dimensions of the brass insert are as following: internal diameter $(6 \mathrm{~mm})$; Outer diameter $(8.3 \mathrm{~mm})$; Length of insert $(8 \mathrm{~mm})$. Photographs of the brass insert and fabricated thermoplastic plastic component are shown in Figs. 4 and 5 respectively.

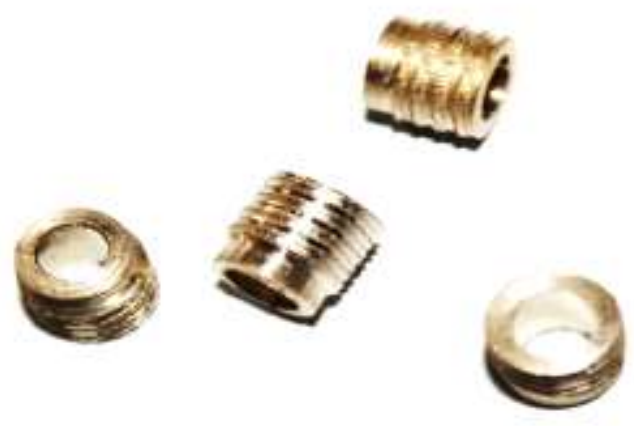

Fig. 4 Standard brass inserts for multiple insertions 


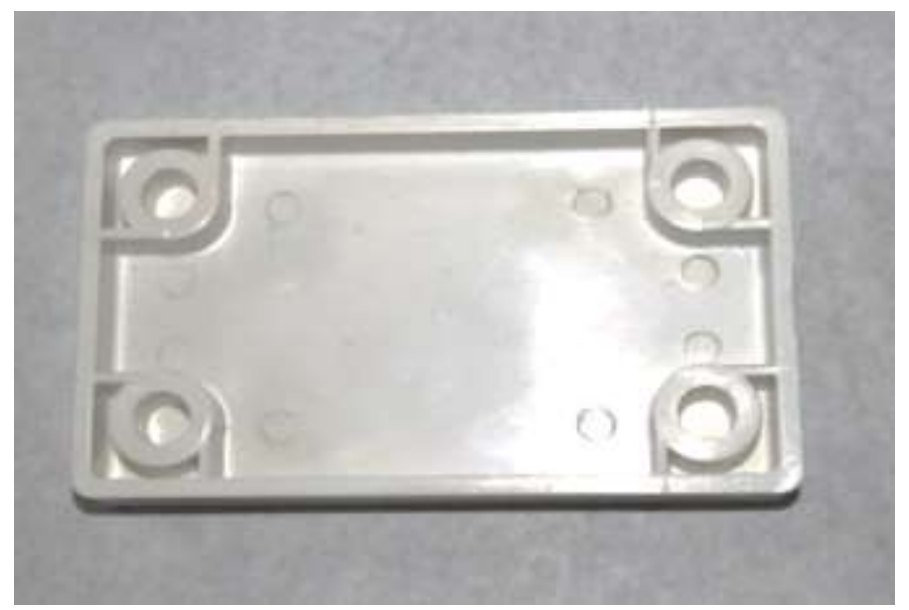

Fig. 5 Fabricated back end cover of eletrical switch box

\section{2 Design of block horn}

Geometries of block horn are selected to match the dimensions of back-end cover of electrical switch box. Length and width of block horn are considered same as length and width of thermoplastic component. Since height of the horn influences the natural frequency of block horn, it is analytically derived from one dimensional wave Eq. (1).

$$
\lambda=\frac{C}{f}=\frac{1}{f} \sqrt{\frac{E}{\rho}}=2 h
$$

where,

$$
\begin{aligned}
& \lambda-\text { Wavelength of mechanical vibrations }(\mu \mathrm{m}) \\
& \mathrm{c}-\text { Velocity of sound }(\mathrm{m} / \mathrm{sec}) \\
& \mathrm{f}-\text { Frequency of vibration }(\mathrm{Hz}) \\
& \text { E - Modulus elasticity of horn material }(\mathrm{GPa}) \\
& \rho-\text { Density of horn material }\left(\mathrm{kg} / \mathrm{m}^{3}\right) \\
& \text { h - Height of the horn }(\mathrm{mm})
\end{aligned}
$$

Aluminium Alloy (AA6351) is selected as horn material for its excellent acoustical properties. The properties of AA 6351 are shown in Table 1.

Table 1 Properties of Aluminium Alloy (AA 6351) [6]

\begin{tabular}{|c|c|c|}
\hline $\begin{array}{c}\text { Young's modulus } \\
(\mathbf{G P a})\end{array}$ & $\begin{array}{c}\text { Poisson's ratio } \\
(\mathbf{v})\end{array}$ & $\begin{array}{c}\text { Density }\left(\mathbf{k g} / \mathbf{m}^{\mathbf{3}}\right) \\
(\boldsymbol{\rho})\end{array}$ \\
\hline 74.5 & 0.33 & 2740 \\
\hline
\end{tabular}

Since the horn is made for an existing ultrasonic insertion machine, its frequency must be matched with machine's frequency $(20 \mathrm{kHz})$. Generally, height of the horn should be multiples of wavelengths of mechanical vibrations generated by block horn. In this study, half wavelength is taken as height of block horn.

Velocity of sound through Aluminium Alloy (AA6351) is calculated using the Eq. (2)

$$
\mathrm{c}=\sqrt{\frac{E}{\rho}}
$$




$$
\begin{aligned}
& =5214 \mathrm{~m} / \mathrm{s} \\
& \text { Wavelength of mechanical vibrations, } \quad \lambda=\frac{C}{f} \\
& =5214 / 20000 \\
& 2 \mathrm{~h}=0.26 \mathrm{~m} \\
& h=\frac{\lambda}{2} \\
& =0.13 \mathrm{~m} \text {. }
\end{aligned}
$$

Height of block horn,

Longitudinal vibration of a block horn can be modeled as an elastic member subjected to axial vibration of a non-prismatic bar. The governing equation of longitudinally vibrating block horn with variable cross section $\mathrm{s}(\mathrm{x})$, is given by the Eq. (3).

$$
\frac{\partial^{2} \mathrm{u}(\mathrm{x}, \mathrm{t})}{\partial \mathrm{t}^{2}}=C^{2}\left[\frac{1}{s(x)} \frac{\partial s(x)}{\partial x} \frac{\partial \mathrm{u}(\mathrm{x}, \mathrm{t})}{\partial \mathrm{x}}+\frac{\partial^{2} \mathrm{u}(\mathrm{x}, \mathrm{t})}{\partial \mathrm{x}^{2}} \mathrm{x}^{2}\right]
$$

where,

\section{$\mathrm{U}(\mathrm{x}, \mathrm{t})$ - Longitudinal displacement}

$\mathrm{X}$ - Co-ordinate in the longitudinal direction and t-time

$\mathrm{s}(\mathrm{x})$ - Cross-sectional area

$\mathrm{C}=\sqrt{E / \rho}=$ Velocity of longitudinal wave

E - Young's modulus and

$\rho$ - Density of horn material

For a uniform block horn, change in area of cross section $\frac{\partial s}{\partial x}=0$. Therefore, Eq. (3) can be written as;

$$
\frac{\partial^{2} \mathrm{u}(\mathrm{x}, \mathrm{t})}{\partial \mathrm{t}^{2}}=C^{2}\left[\frac{\partial^{2} \mathrm{u}(\mathrm{x}, \mathrm{t})}{\partial \mathrm{x}^{2}} \mathrm{x}^{2}\right]
$$

Eq. (4) is also called as the wave equation and the general solution for the displacement ' $U$ ' is given by Eq. (5).

$$
\mathrm{U}=(\mathrm{A} \cos \omega \mathrm{t}+\mathrm{B} \sin \omega \mathrm{t})\left(\mathrm{C} \cos \left(\frac{\omega}{c}\right) \mathrm{x}+\mathrm{D} \sin \left(\frac{\omega}{c}\right) \mathrm{x}\right)
$$

The ends of the horn are free to move in the axial direction and the transverse movement is restricted during ultrasonic insertion. Thus, the boundary conditions for the free-free vibrations are that at the ends of the horn, the stress is minimum and the strain is zero, given by;

$$
\text { At } \mathrm{x}=0 \text { and } \mathrm{x}=1 ; \frac{\partial u}{\partial x}=0
$$

Applying the boundary conditions and solving the Eq. (5), the following modal parameters of the horn are obtained.

1. Natural Frequency $\omega_{\mathrm{n}}$ is given by $\omega_{\mathrm{n}}=\frac{n \pi}{L} \sqrt{E / \rho}$

$$
\mathrm{f}=\frac{n}{2 L} \sqrt{E / \rho}
$$

2. Displacement ' $\mathrm{U}$ ' is given by $\mathrm{U}=\mathrm{D} \cos \left(\frac{n \pi}{L}\right) \mathrm{x}$

(maximum at $\mathrm{x}=0$ and $\mathrm{x}=\mathrm{L}$ )

where $\mathrm{D}=23.4 \mu \mathrm{m}$ (The displacement amplitude at the booster end) 
Determining modal properties of cylindrical type of horn is simple. For non-cylindrical shapes, analytical determination of modal properties is complicated as change in cross sectional area is to be as shape function. So, Finite Element Method is adopted to determine the modal properties of slotted block horn.

\subsection{Finite element analysis of slotted block horn}

Dynamic characteristic of ultrasonic block horn is studied using finite element method. Three types of analyses are carried out namely modal, harmonic and thermal analysis. The modal analysis is used to determine the natural frequency and mode shapes of horn. Design of horn is modified until the longitudinal mode is obtained. Once the longitudinal mode is obtained, the frequency at which the longitudinal mode occurs should be in the range of machine's frequency. This is carried out by preliminary analysis. After getting the longitudinal mode shape in the machine's frequency range, the harmonic analysis is carried out. In harmonic analysis, displacement amplitude at the output face of block horn and von-Mises induced in the horn are predicted by applying boundary conditions. In thermal analysis, the temperature developed at joint is predicted using displacement amplitude which is obtained from harmonic analysis. Methodology adopted for performing FEA is shown in Fig. 6. 


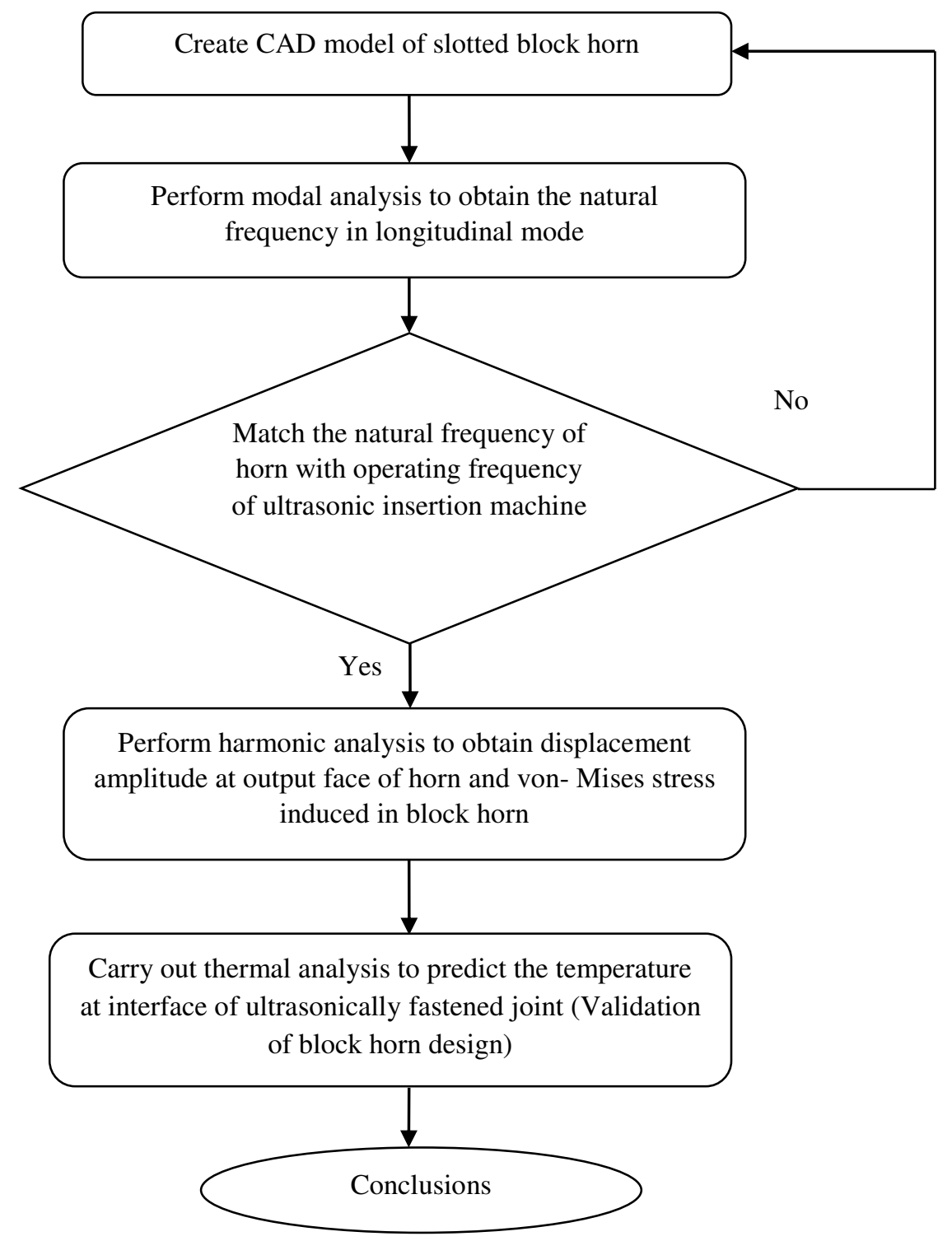

Fig. 6 Methodology adopted for computational modelling of block horn

The slotted block horn is designed with vertical slot and analyzed for uniform nodal displacement. Initially, the block horn is modelled and saved as parasolid (.xt) format. The model of block horn is imported in analysis software to carryout modal analysis. The model is meshed using Tetra 10 node 187 SOLID element with fine mesh size of 3. Solid 187 element has behaviour of quadratic displacement and best suited for modelling irregular meshes. It is defined by 10 nodes and the element has three degrees of freedom at each node (Translations in $\mathrm{x}, \mathrm{y}$ and $\mathrm{z}$ direction). The element has the capability of creep, stress, stiffening, plasticity, hyper elasticity, large deflection and large strain. Also, it has the ability to stimulate deformations of fully incompressible hyper elastic materials and 103 nearly incompressible elasto-plastic materials. Positive pressure is given into the element. Material model is specified as linear, elastic, isotropic and properties of aluminium alloy such as modulus of elasticity, poisson's ratio and density are given as input. Mode extractions are carried out between the frequency range of $17-21 \mathrm{kHz}$ using Block Lanchoz option. The results obtained from modal analysis of block horn with vertical slots is represented in Fig. 7. 
From Fig. 7, it is understood that the initial design of block horn underwent excessive deformation in both axial and torsional modes. In addition to that, the displacement amplitude developed at the output face of horn is not uniformly distributed.

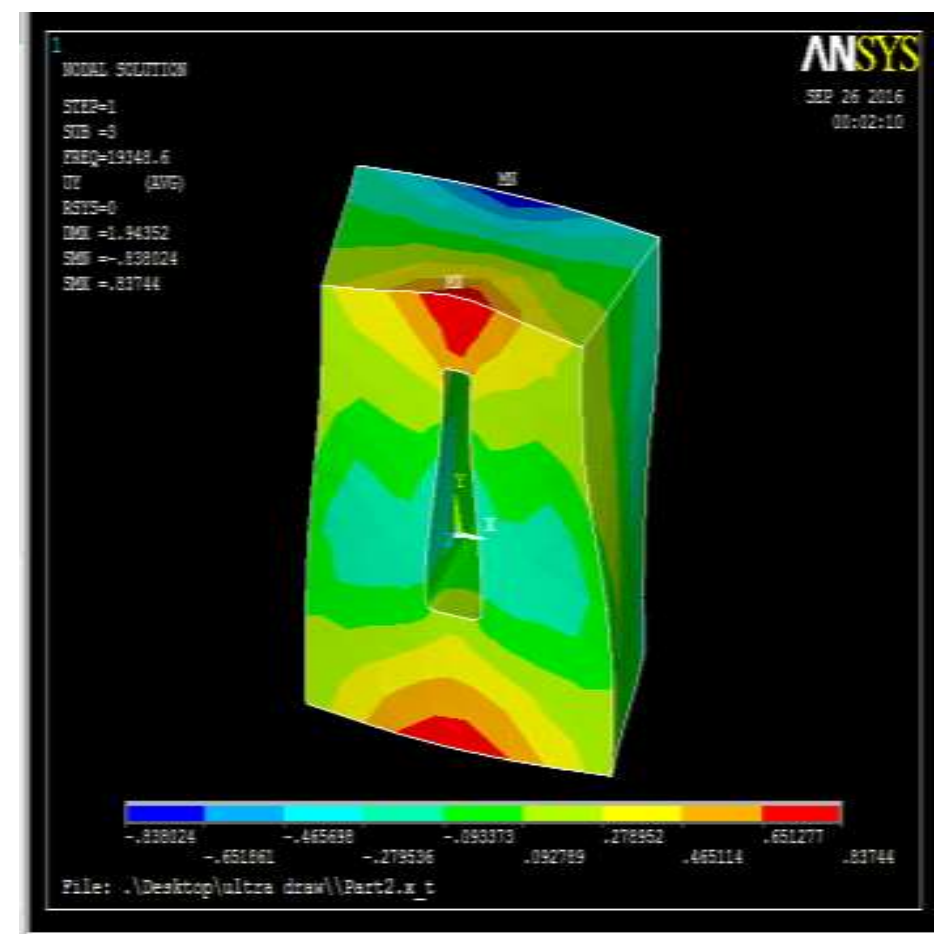

Fig. 7 Modal analysis of horn with vertical slot

To overcome these issues, a groove is made at the output face of slotted block horn to reduce mass and to obtain uniform displacement amplitude. Dimensions of groove are decided by considering the following constraints.

i. Minimum face area required for the horn to ensure proper transfer of load during insertion.

ii. Amplitude uniformity at output end face of slotted block horn.

By keeping above conditions, design of block horn is analyzed to fix the groove dimensions and to obtain uniform amplitude with minimum deformation. From the primary analysis, the height and width of the groove are fixed as $20 \mathrm{~mm}$ and $45 \mathrm{~mm}$ respectively which are shown in Fig. 8. After finalizing the groove dimensions, four design variables, viz. slot length $\left(\mathrm{X}_{1}\right)$, slot width $\left(\mathrm{X}_{2}\right)$, distance of the slot from the bottom end face of horn $\left(\mathrm{X}_{3}\right)$ and height of the horn $\left(\mathrm{X}_{4}\right)$ are considered for optimizing the design of block horn. The location of the slot in block horn with design variables are shown in Fig. 8. 


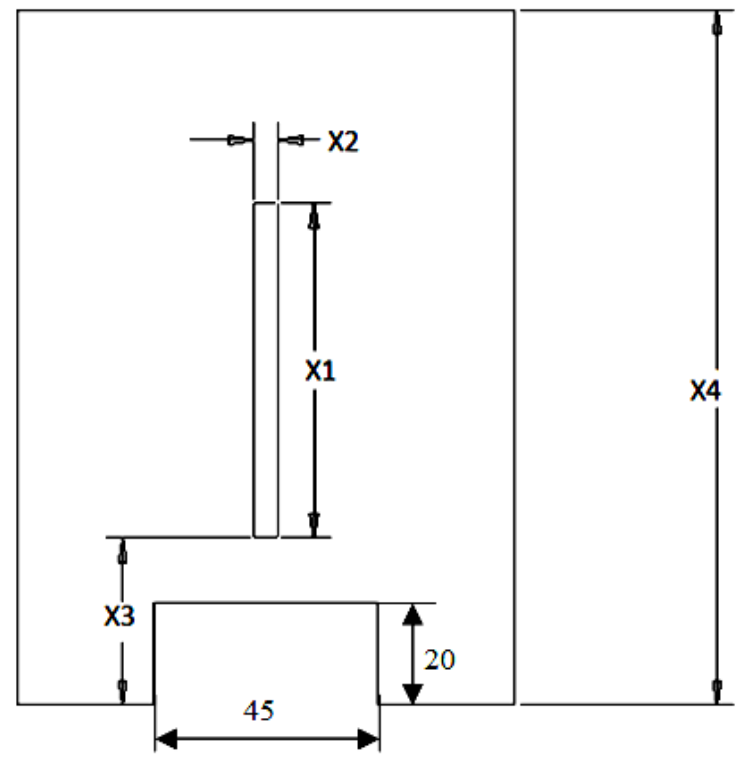

Fig. 8 Dimensions of slotted block horn

\subsection{Response surface modelling}

Response surface methodology (RSM) is a statistical method which is applied for modelling and analyzing the problems in which a response parameter is influenced by several variables and the objective is to either maximize or minimize the response parameter. In this study, acoustic analyses are planned as per face centred central composite design of experiments. Planned acoustic analyses require a certain number of combinations of design variables and levels. From the preliminary analysis range for each design variables are finalized. Various combinations of design variables are obtained by adopting Response Surface Methodology. Design variables and their levels are shown in Table 2.

Table 2 Design variables of block and their levels

\begin{tabular}{|c|c|c|c|}
\hline \multirow{2}{*}{$\begin{array}{c}\text { Design } \\
\text { Variables }\end{array}$} & \multicolumn{3}{|c|}{ Levels (mm) } \\
\cline { 2 - 4 } & $\mathbf{- 1}$ & $\mathbf{0}$ & $\mathbf{+ 1}$ \\
\hline $\mathrm{X}_{1}$ & 60 & 65 & 70 \\
\hline $\mathrm{X}_{2}$ & 4.5 & 5 & 5.5 \\
\hline $\mathrm{X}_{3}$ & 30 & 32.5 & 35 \\
\hline $\mathrm{X}_{4}$ & 130 & 135 & 140 \\
\hline
\end{tabular}

Face centred central composite design of experiments is utilized for obtaining various combinations of design variables. The central composite design (CCD) contains of 16-factorial points, 7-center points and 8-axial points. A set of 31 combinations of design variables is considered for acoustic analyses of slotted block horn. Natural frequencies of block horn obtained for various combinations of design variables from modal analysis are shown in Table 3. Figs. 9 and 10 show the results obtained from modal analysis for few combinations of design variables. 
Table 3 Natural frequency of slotted block horn for different combinations of design variables

\begin{tabular}{|c|c|c|c|c|c|}
\hline S.No & $\begin{array}{c}\mathbf{X}_{1} \\
(\mathbf{m m})\end{array}$ & $\begin{array}{c}\mathbf{X}_{2} \\
(\mathbf{m m})\end{array}$ & $\begin{array}{c}\mathbf{X}_{3} \\
(\mathbf{m m})\end{array}$ & $\begin{array}{c}\mathbf{X}_{4} \\
(\mathbf{m m})\end{array}$ & $\begin{array}{l}\text { Natural frequency of horn } \\
\qquad(\mathbf{H z})\end{array}$ \\
\hline 1 & 65 & 5 & 32.5 & 135 & 19728 \\
\hline 2 & 60 & 5 & 32.5 & 135 & 19751 \\
\hline 3 & 65 & 5 & 35 & 135 & 19759 \\
\hline 4 & 65 & 5 & 32.5 & 135 & 19728 \\
\hline 5 & 70 & 4.5 & 30 & 140 & 19028 \\
\hline 6 & 60 & 4.5 & 30 & 140 & 19080 \\
\hline 7 & 70 & 5.5 & 30 & 130 & 20367 \\
\hline 8 & 70 & 4.5 & 35 & 140 & 19092 \\
\hline 9 & 60 & 5.5 & 35 & 140 & 19078 \\
\hline 10 & 65 & 4.5 & 32.5 & 135 & 19753 \\
\hline 11 & 65 & 5 & 32.5 & 135 & 19728 \\
\hline 12 & 70 & 5.5 & 35 & 140 & 19036 \\
\hline 13 & 70 & 4.5 & 30 & 130 & 20421 \\
\hline 14 & 65 & 5 & 32.5 & 135 & 19728 \\
\hline 15 & 60 & 4.5 & 35 & 130 & 20533 \\
\hline 16 & 65 & 5 & 32.5 & 135 & 19728 \\
\hline 17 & 70 & 4.5 & 35 & 130 & 20500 \\
\hline 18 & 65 & 5 & 32.5 & 140 & 19050 \\
\hline 19 & 60 & 5.5 & 30 & 130 & 20419 \\
\hline 20 & 70 & 5 & 32.5 & 135 & 19712 \\
\hline 21 & 65 & 5.5 & 32.5 & 135 & 19699 \\
\hline 22 & 70 & 5.5 & 30 & 140 & 18975 \\
\hline 23 & 65 & 5 & 32.5 & 135 & 19728 \\
\hline 24 & 60 & 5.5 & 30 & 140 & 19035 \\
\hline 25 & 60 & 5.5 & 35 & 130 & 20474 \\
\hline 26 & 65 & 5 & 32.5 & 130 & 20450 \\
\hline 27 & 65 & 5 & 30 & 135 & 19700 \\
\hline 28 & 60 & 4.5 & 30 & 130 & 20468 \\
\hline 29 & 60 & 4.5 & 35 & 140 & 19128 \\
\hline 30 & 65 & 5 & 32.5 & 135 & 19728 \\
\hline 31 & 70 & 5.5 & 35 & 130 & 20445 \\
\hline
\end{tabular}




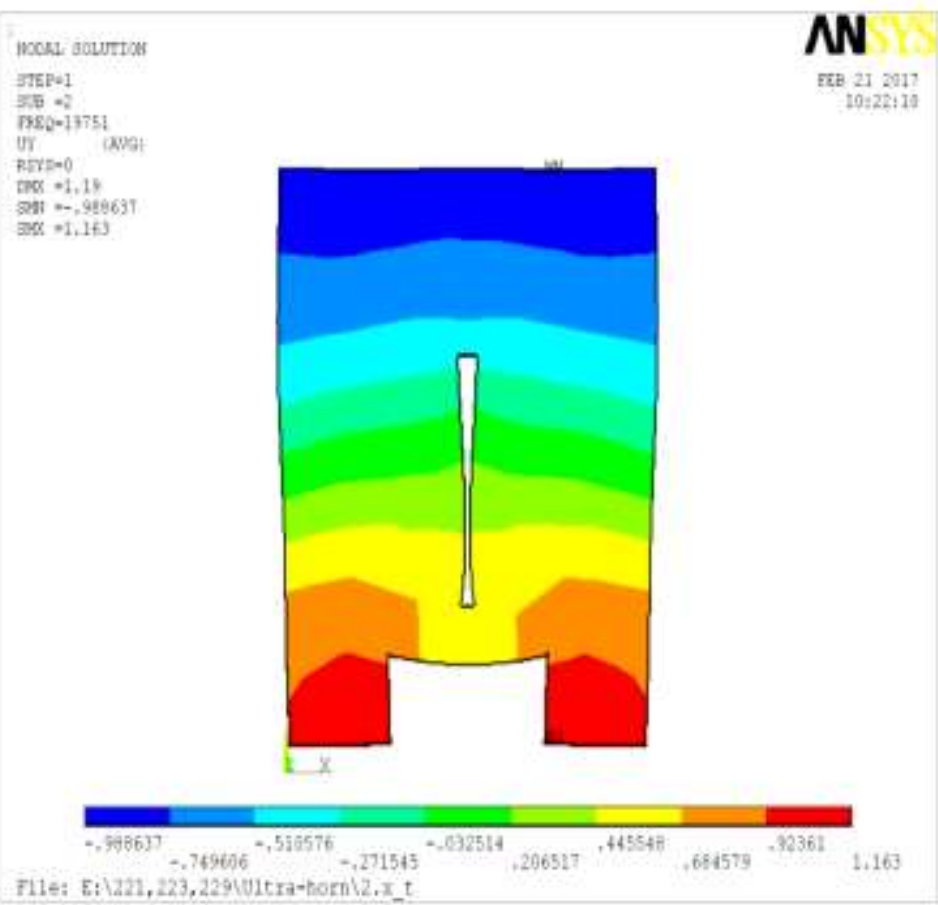

Fig. 9 Modal analysis for $2^{\text {nd }}$ combination of design variables

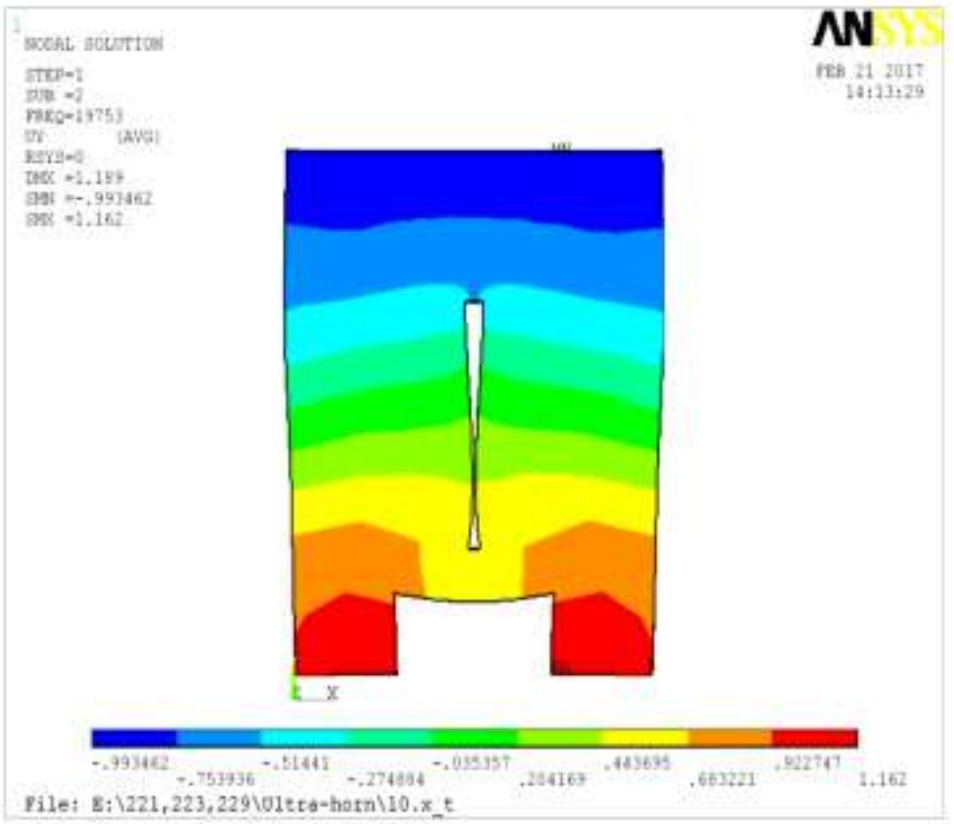

Fig. 10 Modal analysis for $10^{\text {th }}$ combination of design variables

Results obtained from modal analysis are shown in Figs. 9 and 10. From the modal analysis, it is observed that the resonant frequencies obtained are within the working range of ultrasonic insertion machine. The vibrations are longitudinal and the output face slotted block horn is perfectly flat which is highly desirable for ultrasonic 
multiple insertion. This significance is well connected with the results detailed by Dipin Kumar et al. [8]. So, all the profiles of the slotted block horns are valid for performing harmonic analysis.

Harmonic analysis is performed to determine the displacement amplitude obtained at output face of horn and stress induced in block horn for given frequency range. The displacement amplitude and resonant frequency obtained from modal analysis are considered for performing harmonic analysis. It is assumed that lateral and rotational movement of the horn are arrested and permitted to oscillate only in longitudinal direction. This axial movement of horn performs encapsulation of brass insert into thermoplastic component. For given dimensions of slotted block horn and machine frequency, amplitude of vibration at output face of block horn is determined using harmonic analysis and the same amplitude is considered for insertion purpose. The displacement amplitude and vonMises stress obtained from harmonic analysis for different combinations of design parameters are shown in Table 4. Figs. 11 and 12 show the displacement amplitude for few combinations of design variable and Figs. 13 and 14 show the stress experienced by the block horn for the same combinations.

Table 4 Results of harmonic analysis for different combinations of the design variables

\begin{tabular}{|c|c|c|c|c|c|c|}
\hline S.No & $\begin{array}{c}\mathbf{X}_{1} \\
(\mathbf{m m})\end{array}$ & $\begin{array}{c}\mathbf{X}_{2} \\
(\mathbf{m m})\end{array}$ & $\begin{array}{c}\mathbf{X}_{3} \\
(\mathbf{m m})\end{array}$ & $\begin{array}{c}\mathbf{X}_{4} \\
(\mathbf{m m})\end{array}$ & $\begin{array}{c}\text { Displacement } \\
\text { amplitude }(\mu \mathrm{m})\end{array}$ & $\begin{array}{c}\text { von-Mises stress } \\
\text { (MPa) }\end{array}$ \\
\hline 1 & 65 & 5 & 32.5 & 135 & 28.7 & 12.4 \\
\hline 2 & 60 & 5 & 32.5 & 135 & 29 & 13.6 \\
\hline 3 & 65 & 5 & 35 & 135 & 29.2 & 10.2 \\
\hline 4 & 65 & 5 & 32.5 & 135 & 28.7 & 12.4 \\
\hline 5 & 70 & 4.5 & 30 & 140 & 27.7 & 12.1 \\
\hline 6 & 60 & 4.5 & 30 & 140 & 28.1 & 16.3 \\
\hline 7 & 70 & 5.5 & 30 & 130 & 28.6 & 13.6 \\
\hline 8 & 70 & 4.5 & 35 & 140 & 28.4 & 13.2 \\
\hline 9 & 60 & 5.5 & 35 & 140 & 28.4 & 13.2 \\
\hline 10 & 65 & 4.5 & 32.5 & 135 & 28.6 & 11.9 \\
\hline 11 & 65 & 5 & 32.5 & 135 & 28.7 & 12.4 \\
\hline 12 & 70 & 5.5 & 35 & 140 & 28.3 & 12 \\
\hline 13 & 70 & 4.5 & 30 & 130 & 28.3 & 15.5 \\
\hline 14 & 65 & 5 & 32.5 & 135 & 28.7 & 12.4 \\
\hline 15 & 60 & 4.5 & 35 & 130 & 29.5 & 13.4 \\
\hline 16 & 65 & 5 & 32.5 & 135 & 28.7 & 12.4 \\
\hline 17 & 70 & 4.5 & 35 & 130 & 28 & 13.3 \\
\hline 18 & 65 & 5 & 32.5 & 140 & 28.2 & 12.5 \\
\hline 19 & 60 & 5.5 & 30 & 130 & 28.8 & 12.1 \\
\hline 20 & 70 & 5 & 32.5 & 135 & 28.1 & 12.4 \\
\hline
\end{tabular}




\begin{tabular}{|c|c|c|c|c|c|c|}
\hline 21 & 65 & 5.5 & 32.5 & 135 & 28.7 & 12.2 \\
\hline 22 & 70 & 5.5 & 30 & 140 & 27.6 & 14 \\
\hline 23 & 65 & 5 & 32.5 & 135 & 28.7 & 12.4 \\
\hline 24 & 60 & 5.5 & 30 & 140 & 28.1 & 15.7 \\
\hline 25 & 60 & 5.5 & 35 & 130 & 29.6 & 13 \\
\hline 26 & 65 & 5 & 32.5 & 130 & 28.8 & 8.7 \\
\hline 27 & 65 & 5 & 30 & 135 & 28.4 & 14 \\
\hline 28 & 60 & 4.5 & 30 & 130 & 28.9 & 18 \\
\hline 29 & 60 & 4.5 & 35 & 140 & 28.8 & 13.3 \\
\hline 30 & 65 & 5 & 32.5 & 135 & 28.7 & 13.1 \\
\hline 31 & 70 & 5.5 & 35 & 130 & 27.9 & \\
\hline
\end{tabular}

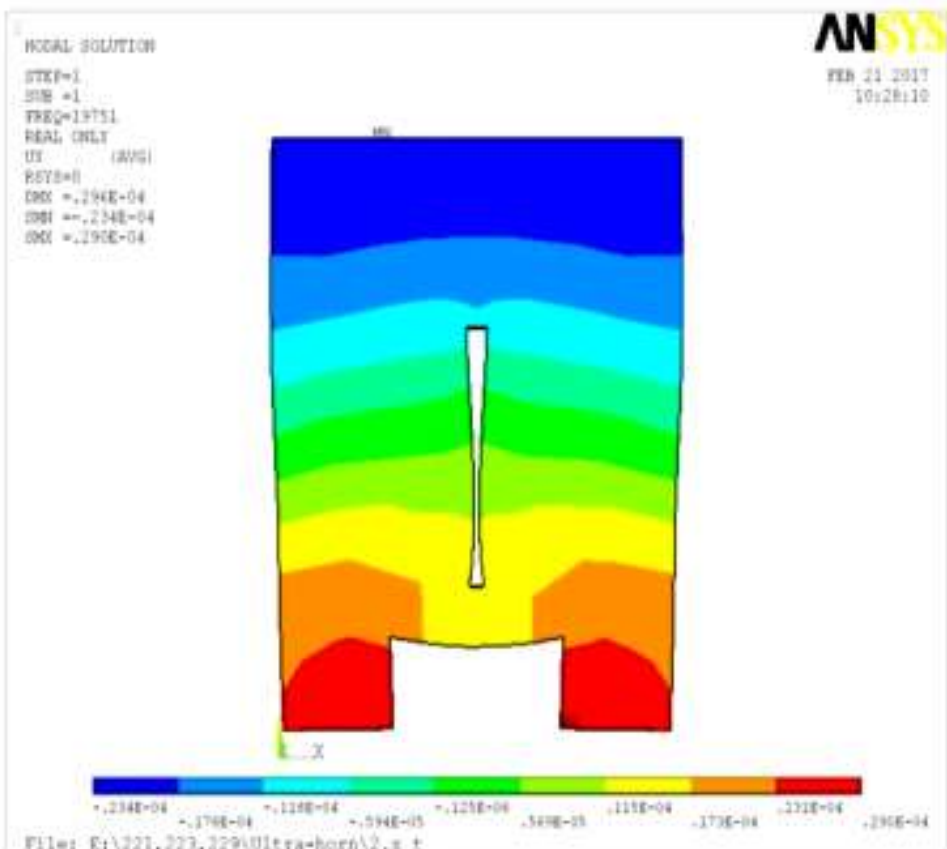

File: Et $1221,223,22$ mulera-tarn 2,1 ,

Fig. 11 Displacement amplitude for $2^{\text {nd }}$ combination of design variables 


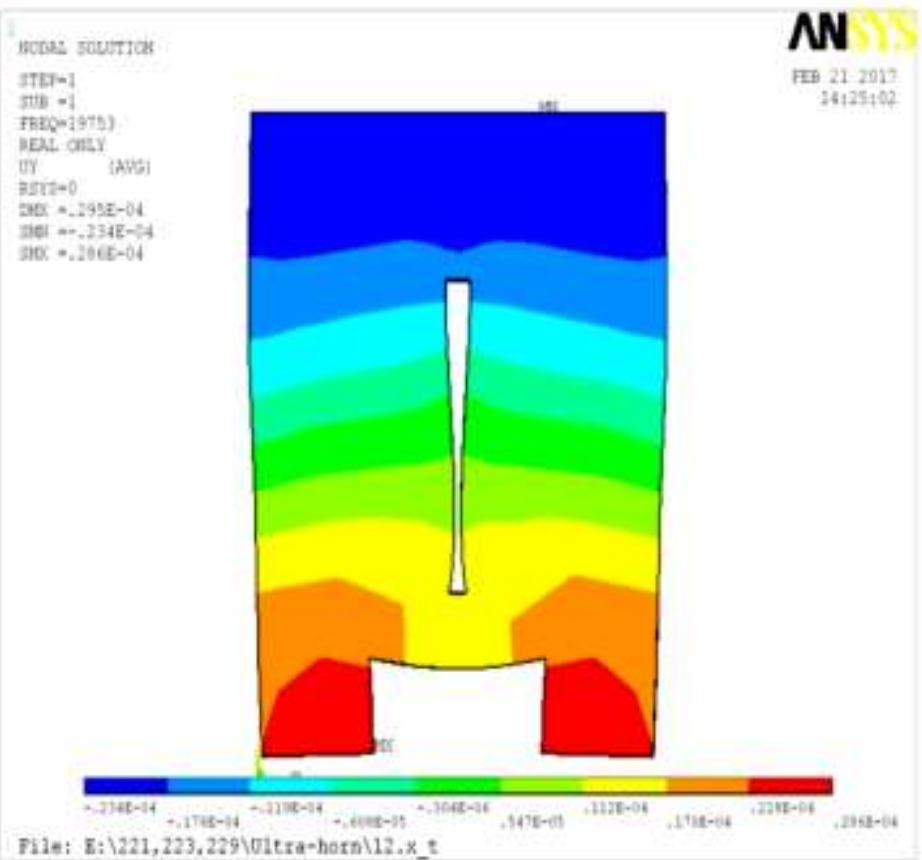

Fig. 12 Displacement amplitude for $10^{\text {th }}$ combination of design variables

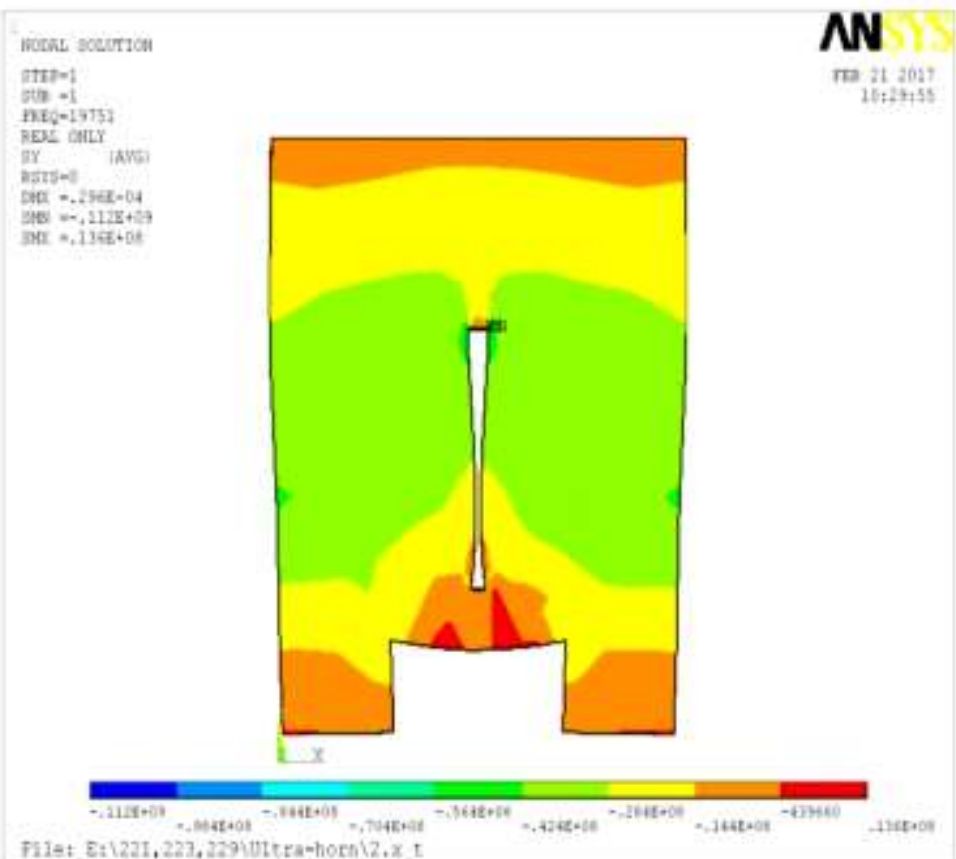

Fig. 13 von-Mises stress induced in block for $2^{\text {nd }}$ combination of design variables 


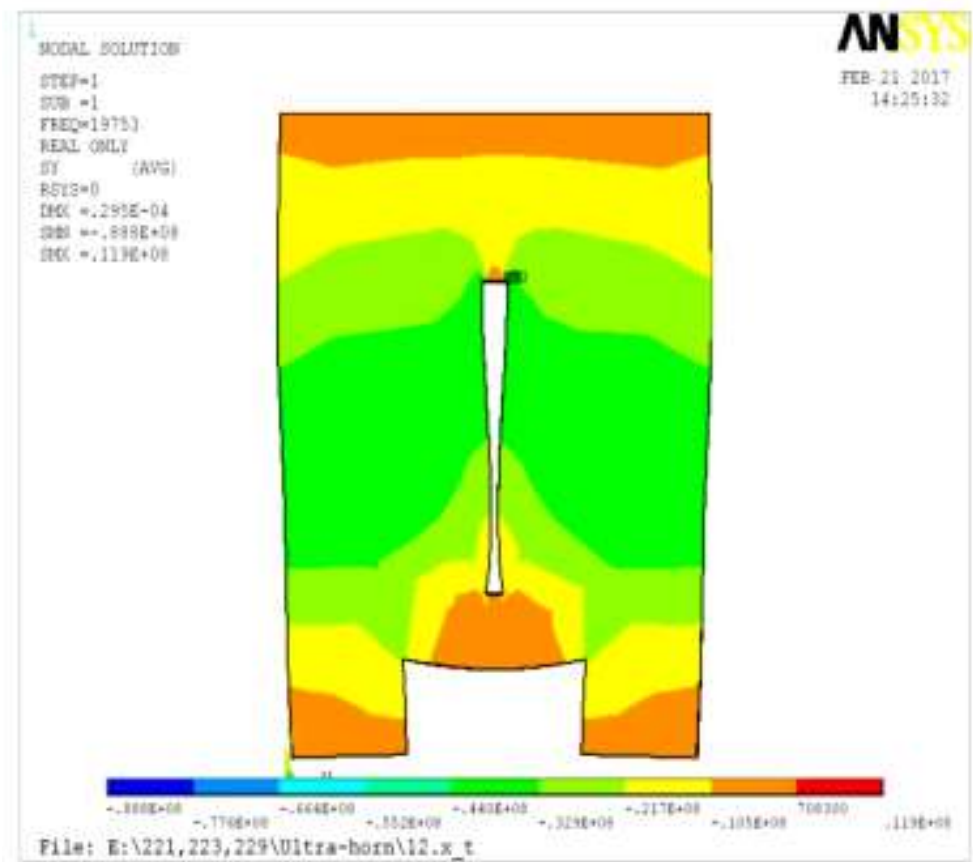

Fig. 14 von-Mises stress induced in block for $10^{\text {th }}$ combination of design variables

From harmonic analysis, maximum displacement amplitude obtained at the output face of block horn is $29.6 \mu \mathrm{m}$ (Table 4). It is also observed that the uniformity of displacement amplitude is $100 \%$ at output face of horn which is in good indenture with previous studies Dipin Kumar et al. [8]. Figures 13 and 14 show the von-Mises stress measured in the slotted block horn. It can be noted that maximum von-stress induced in the horn is $16.3 \mathrm{MPa}$ which appears very small region near to the slot of block horn, while the stress across the block horn surface, booster end of horn and out face of horn are much lower than the fatigue strength of Aluminium alloy AA 6351 (131 $\mathrm{MPa}$ ). This is good in agreement with results conveyed by Kumar et al. [10]. So, the design of slotted block horn can be considered safe within the design parameters and metallurgical limit.

Table 5 shows the influence of various design variables on displacement amplitude. From the Table 5, it is noticed that design variable $\mathrm{X}_{1}$ (slot length) is most influential parameter. The mean value for amplitude of vibration is given in Fig. 15. From the figure of main effect plot for amplitude of vibration, it is observed that the displacement amplitude at the output face of horn depend on all the four design variables.

Table 5 Average displacement amplitude of vibration at various levels of design parameters

\begin{tabular}{|c|c|c|c|c|c|}
\hline \multirow{2}{*}{$\begin{array}{c}\text { Design } \\
\text { Variables }\end{array}$} & $\mathbf{1}$ & $\mathbf{2}$ & $\mathbf{3}$ & \multirow{2}{*}{ Difference } & Rank \\
\cline { 2 - 5 } & $\mathbf{2 8 . 8 0 0}$ & 28.667 & 28.100 & 0.700 & 1 \\
\hline $\mathbf{X}_{\mathbf{1}}$ & 28.478 & $\mathbf{2 8 . 6 6 2}$ & 28.444 & 0.218 & 4 \\
\hline $\mathbf{X}_{\mathbf{2}}$ & 28.278 & 28.638 & $\mathbf{2 8 . 6 7 8}$ & 0.400 & 3 \\
\hline $\mathbf{X}_{3}$ & $\mathbf{2 8 . 7 1 1}$ & 28.685 & 28.178 & 0.533 & 2 \\
\hline $\mathbf{X}_{4}$ & & &
\end{tabular}




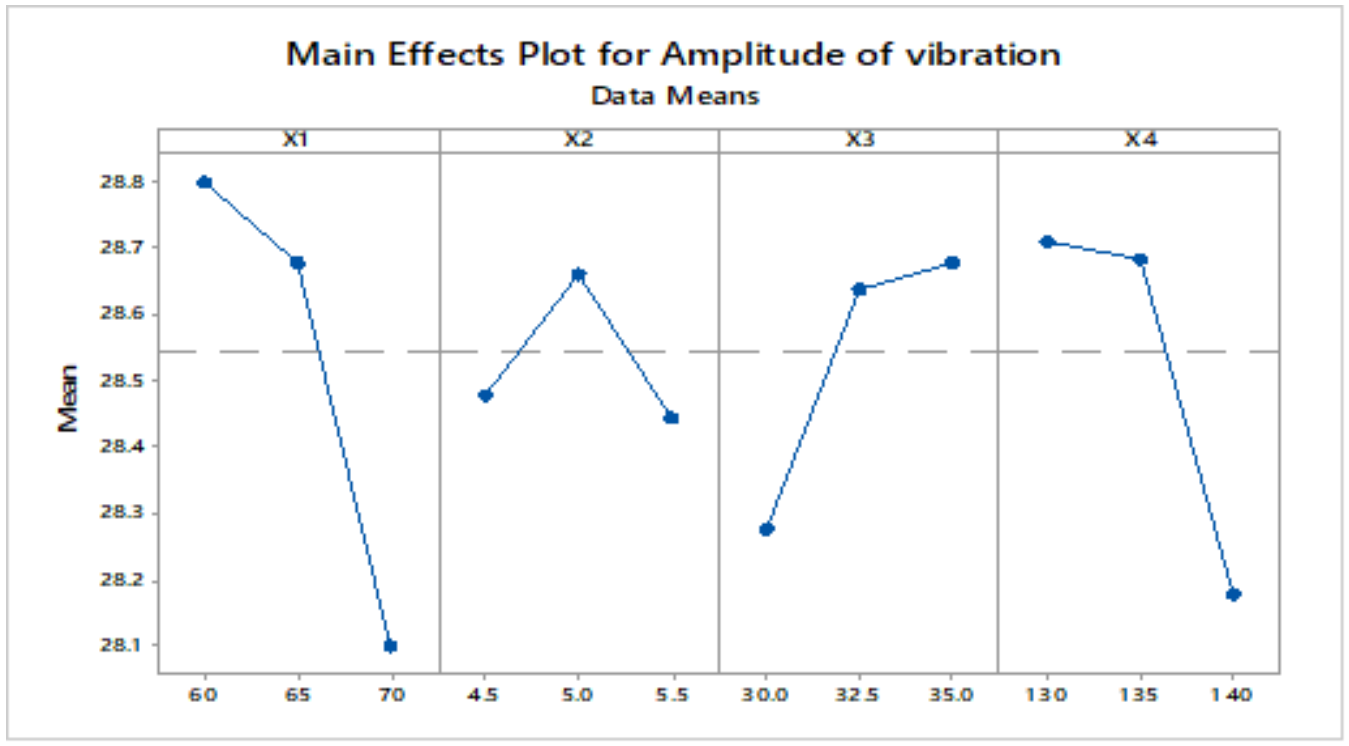

Fig. 15 Mean values of amplitude of vibration at various levels of design variables

Second order polynomial model have been developed for establishing the relationship between design variables of slotted block horn and displacement amplitude. Polynomial equation for four design variables considered in the present study is given in Eq. (8).

$$
y_{i}=\beta_{0}+\sum_{j=1}^{3} \beta_{j} x_{j}+\sum_{j=1}^{3} \beta_{j j} x_{j}^{2}+\sum_{i=1}^{2} j \sum_{j=i+1}^{3} \beta_{i j} x_{i} x_{j}
$$

where, $y_{i}$ is the response, i.e., displacement amplitude; $x_{j}$ represents design variables $X_{1}, X_{2}, X_{3}$ and $X_{4} ; \beta_{0}$, $\beta_{\mathrm{j}}, \beta_{\mathrm{jj}}$, and $\beta_{\mathrm{ij}}$ represent the constant, linear, quadratic, and interaction terms, respectively.

Based on the results obtained from FEA, non-linear model for displacement amplitude is developed using RSM to represent the relationship between design variables and response is given in Eq. (9).

Displacement amplitude $=52-1.38 X_{1}+39.2 X_{2}+4.72 X_{3}-2.24 X_{4}+0.01028 X_{1}^{2}-2.772 X_{2}^{2}-0.0549 X_{3}^{2}+$ $0.01028 \mathrm{X}_{4}^{2}+0.0125 \mathrm{X}_{1} \mathrm{X}_{2}-0.0105 \mathrm{X}_{1} \mathrm{X}_{3}+0.00225 \mathrm{X}_{1} \mathrm{X}_{4}+0.045 \mathrm{X}_{2} \mathrm{X}_{3}-0.1025 \mathrm{X}_{2} \mathrm{X}_{4}-0.00550 \mathrm{X}_{3} \mathrm{X}_{4}$

\section{Optimization of slotted block horn dimensions using Genetic Algorithm}

Higher displacement amplitude at the output face of block horn can be achieved uniformly and effectively by optimizing design parameters using suitable non-traditional optimization technique. So, it needs an efficient optimization technique to find the optimum combination of design variables which improves the amplitude uniformity. GA is such optimization technique works based on the principles of natural selection and genetics. As GA works based on string coded variables instead of variables, it provides better results than traditional optimization techniques. The benefit of working with coded variables is forbidden combination of design variables are put aside which results in obtaining maximum displacement amplitude. The non-linear model developed for displacement amplitude of vibration from RSM is used as fitness function in GA.

Design optimization of slotted block horn was performed using GA. Input fitness function is given in Eq. (4), the constraints for insertion process are given in Eqs. (10), (11), (12), (13) and GA parameters shown in Table 6 are considered for the design optimization of slotted block horn to maximize the displacement amplitude. GA Tool box of MATLAB is utilized to optimize the design of slotted block horn. 
Figs. 16 and 17 show the results obtained from GA Tool box. Fig. 16 shows the optimized value of displacement amplitude and optimum conditions of design variables are shown in Fig. 17. Fig. 18 and Table 7 show the optimum geometry of slotted block obtained through GA tool box.

$$
\begin{aligned}
& 60 \mathrm{~mm} \leq \mathrm{X}_{1} \leq 70 \mathrm{~mm} \\
& 4.5 \mathrm{~mm} \leq \mathrm{X}_{2} \leq 5.5 \mathrm{~mm} \\
& 30 \mathrm{~mm} \leq \mathrm{X}_{3} \leq 35 \mathrm{~mm} \\
& 130 \mathrm{~mm} \leq \mathrm{X}_{4} \leq 140 \mathrm{~mm}
\end{aligned}
$$

\begin{tabular}{|c|c|}
\hline Types of operation and parameter & Functions or parameters value used \\
\hline Population type & Double vector \\
\hline Population size & 50 \\
\hline Creation Function & Constraint dependant \\
\hline Scaling Function & Rank \\
\hline Selection Function & Tournament \\
\hline Elite count & 2 \\
\hline Crossover fraction & 0.8 \\
\hline Mutation function & Uniform \\
\hline Mutation rate & 0.007 \\
\hline Crossover function & Heuristic \\
\hline Crossover rate & 0.8 \\
\hline Direction & Forward \\
\hline Fraction & 0.2 \\
\hline Interval & 20 \\
\hline Generations & 100 \\
\hline Stall generation & 50 \\
\hline Function tolerance & $1.00 \mathrm{E}-06$ \\
\hline
\end{tabular}

Table 6 GA parameter for optimizing the design variables 


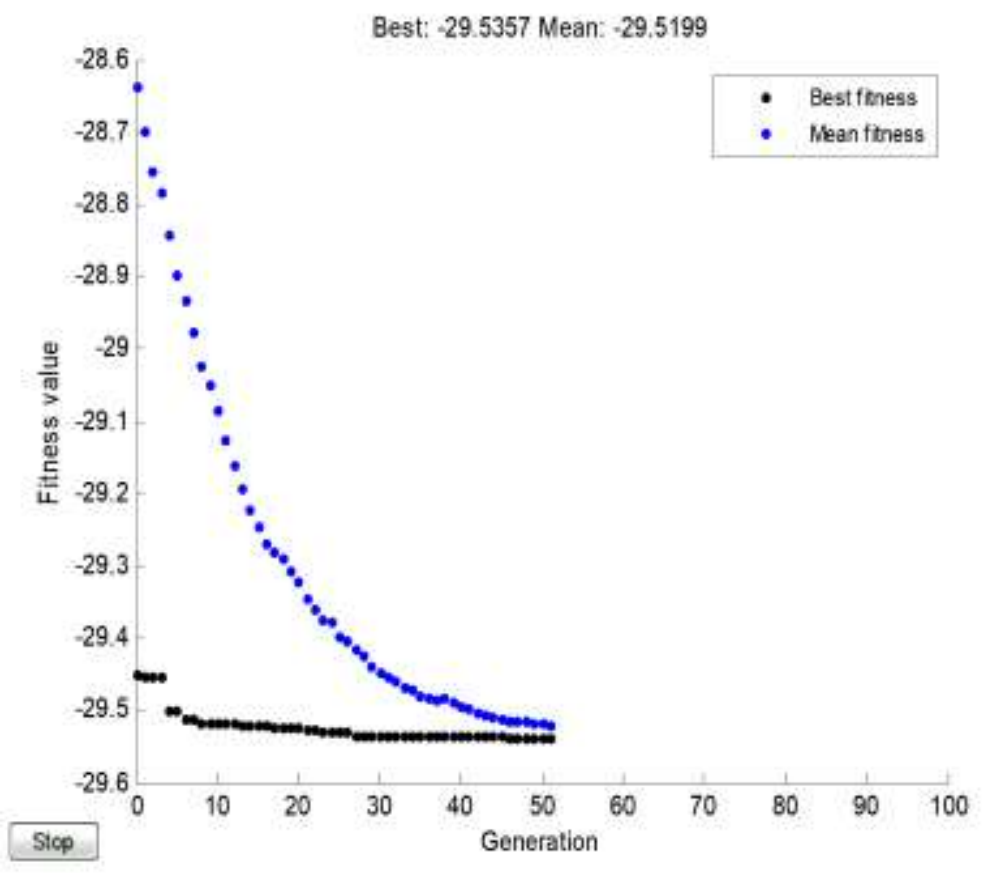

Fig. 16 Convergence of fitness value

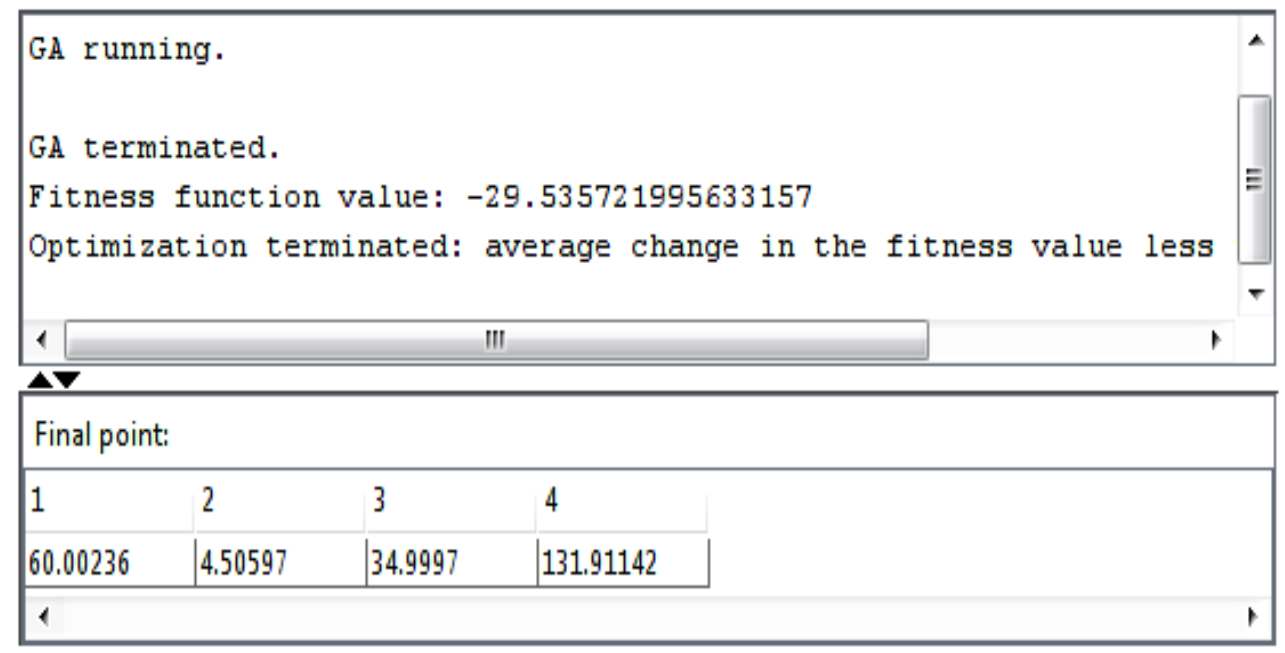

Fig. 17 Converged values of design variables 

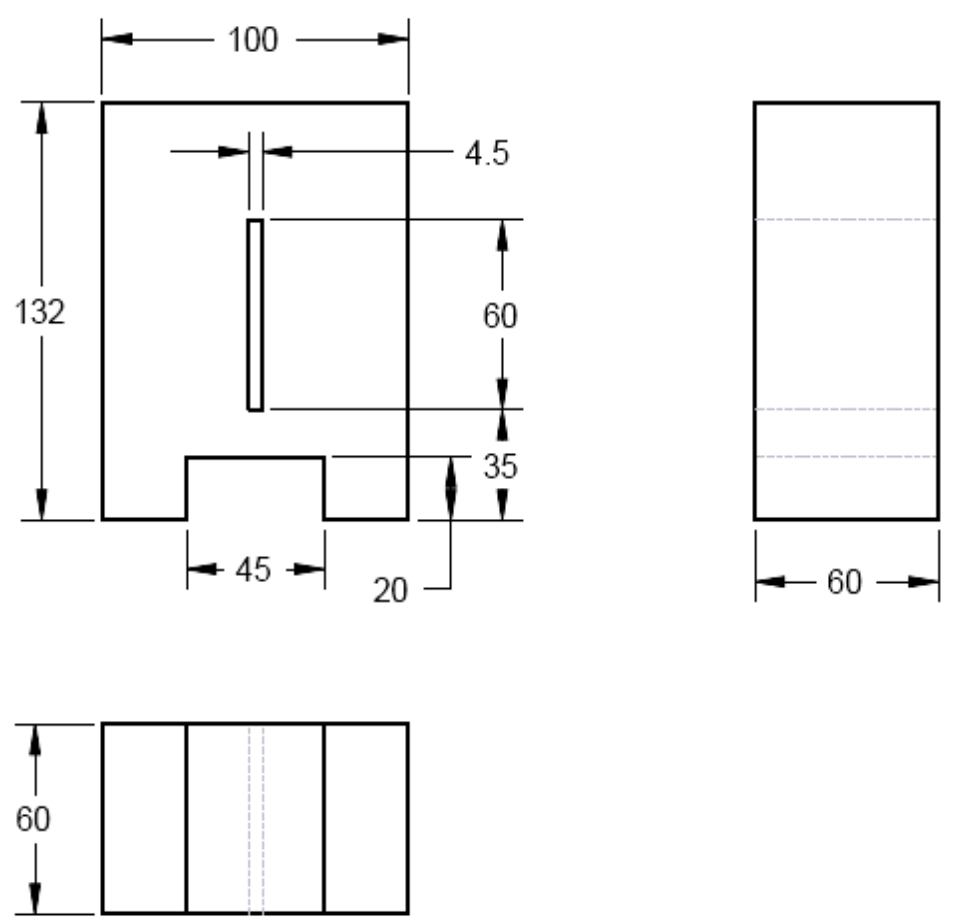

Fig. 18 Optimum design of slotted block horn

Table 7 Optimized dimensions of slotted block horn using GA

\begin{tabular}{|c|c|c|c|}
\hline \multicolumn{4}{|c|}{ Optimized design variables of slotted block horn (mm) } \\
\hline $\mathbf{X}_{\mathbf{1}}$ & $\mathbf{X}_{\mathbf{2}}$ & $\mathbf{X}_{\mathbf{3}}$ & $\mathbf{X}_{\mathbf{4}}$ \\
\hline 60 & 4.5 & 35 & 132 \\
\hline
\end{tabular}

\section{Validation of optimal design of block horn}

\subsection{Theoretical validation through simulation}

The modal and harmonic analyses are carried out to validate the optimum design of slotted block horn obtained from GA. Fig. 19 shows the longitudinal mode of slotted block occurs at frequency of $20496 \mathrm{~Hz}$. This frequency is within the operating frequency of ultrasonic insertion machine. Also, it was observed that the vibration is purely in longitudinal direction and output face of block horn is perfectly flat which is highly desirable design objective of the slotted block horn [8]. The harmonic analysis results of optimum design of block horn are shown in Fig. 20. It can be seen from figure, the maximum displacement amplitude obtained along the longitudinal mode of vibration $(20496 \mathrm{~Hz})$ is $29.5 \mu \mathrm{m}$ and it occurs at the free end (output face) of block horn. Further the performance of optimum design of slotted block horn has to validated theoretically through thermal analysis by predicting the temperature at ultrasonically fastened joint. 


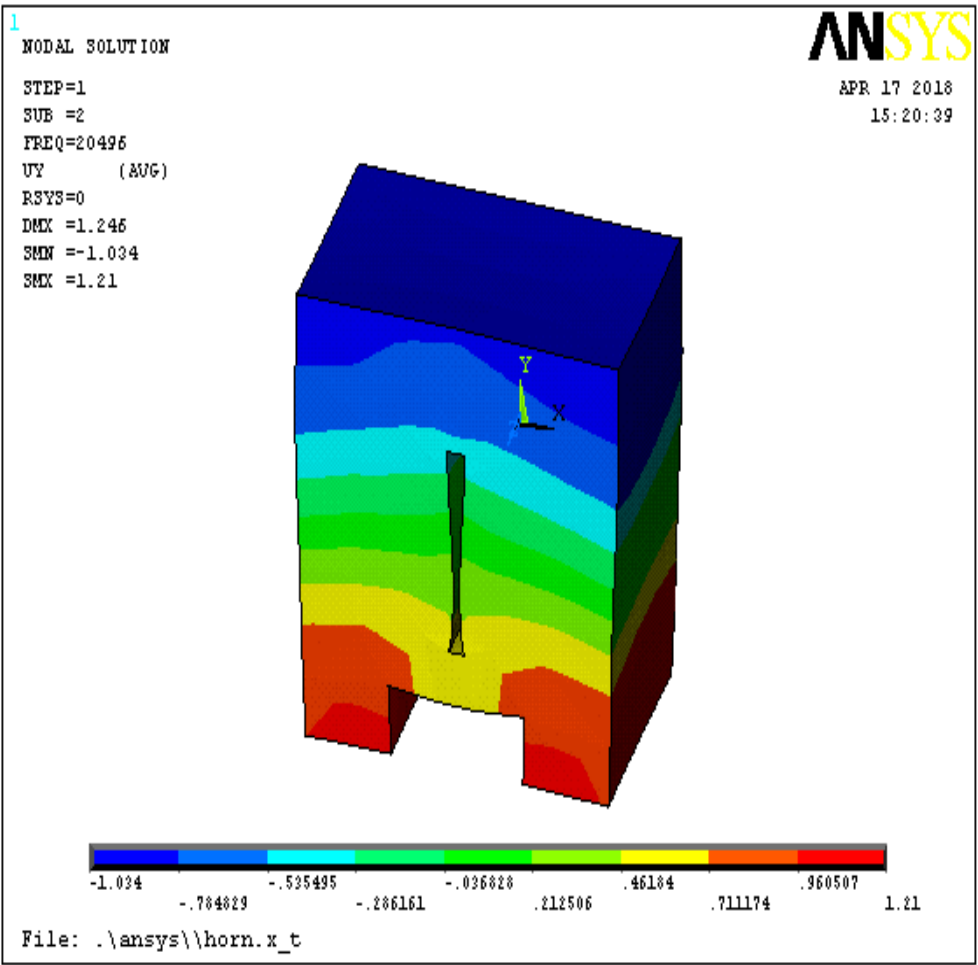

Fig. 19 Modal analysis for optimum design of slotted block horn

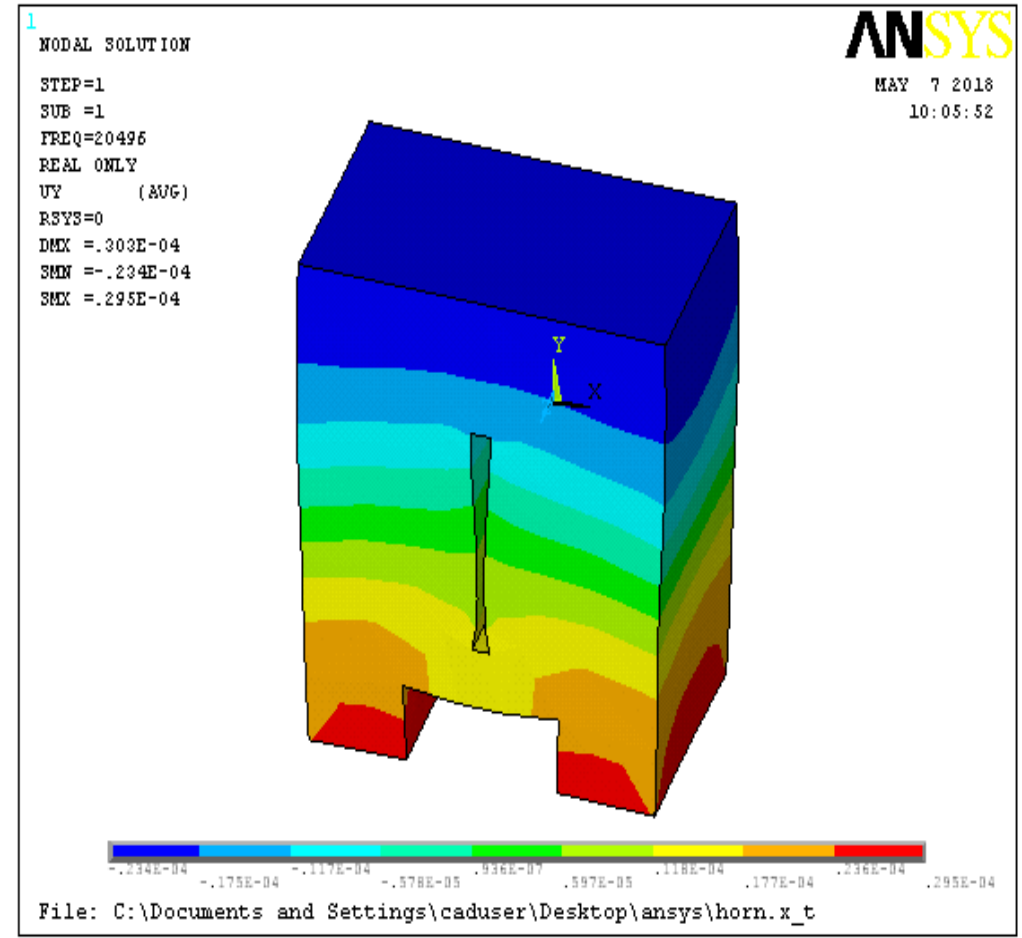

Fig. 20 Harmonic analysis for optimum design of slotted block horn 
Thermal analysis was performed on ABS thermoplastic electrical switch box to find the temperature at joint and also to check the dimensional stability of mounting hole during ultrasonic insertion process. The mechanism behind ultrasonic insertion process is viscoelastic heating which occurs when thermoplastic material is subjected to high frequency of vibration. In ultrasonic insertion, heat developed at joint is direct indicator of insertion quality which is directly proportional to square of displacement amplitude, ultrasonic frequency and loss modulus of thermoplastic material and is given in Eq. (14).

$$
\begin{aligned}
& \text { Heat developed at joint } \mathrm{Q}=\frac{\omega \varepsilon^{2} \mathrm{E}^{\prime \prime}}{2} \mathrm{~J} / \mathrm{m}^{3} \mathrm{~s} \\
& \text { where, } \\
& \omega \text { - Natural frequency }(2 \pi f) \text {, } \\
& \varepsilon \text { - Strain amplitude (ratio of displacement amplitude at tip of horn to the length } \\
& \text { of ABS test specimen) } \\
& \text { E' - Loss modulus of the thermoplastic material }\left(0.42 \times 10^{9}\right)
\end{aligned}
$$

Heat flux at joint interface is calculated from the following equation and expressed in $\mathrm{W} / \mathrm{m}^{2}$.

Heat flux at joint $Q^{\prime}=\mathrm{Q} \times$ Interference between insert and thermoplastic material $\left(0.5 \times 10^{-3}\right) \times$ Energy absorption ratio of $\mathrm{ABS}(0.485)$

During ultrasonic insertion the block horn comes into contact with metal insert and transfers the ultrasonic vibrations to the metal insert then these vibrations reach the interface of metal insert and thermoplastic component where fastening takes place. As ultrasonic insertion is kind of far-field joining process the portion of developed heat at joint is utilized for insertion and remaining is lost due to viscous dissipation. Energy absorption ratio is defined as the ratio of energy absorbed by thermoplastic material at joint to the energy dissipated by the ultrasonic horn. For ABS thermoplastic material energy absorption ratio is $48.5 \%$ [19]. From the differential scanning calorimetry curves (DSC curves) the glass transition temperature for $\mathrm{ABS}$ is $100.49^{\circ} \mathrm{C}$, when the temperature increases $\mathrm{ABS}$ thermoplastic will reach its melting point around $433.1^{\circ} \mathrm{C}$. Since ultrasonic insertion is carried out below the melting point of ABS thermoplastic material, the change in enthalpy is not considered during thermal analysis. Three dimensional ten-noded solid 87 element is selected for thermal analysis of the component using FEA. The element has one degree of freedom at each node (Temperature). The element can be applied for 3-D, steady-state or transient thermal analysis. Heat flux obtained from Eq. (15) was applied on inner surface of ABS thermoplastic mounting hole which is the interface of brass insert and thermoplastic component. Convective heat transfer co-efficient of 0.1 $\mathrm{J} / \mathrm{m}^{2}{ }^{\circ} \mathrm{C}[6]$ and room temperature are given as the boundary conditions to carryout thermal analysis which is carried out for a time step size of $3 \mathrm{sec}$ (insertion time) and step size of 0.1 . The result obtained from thermal analysis is shown in Fig. 21 and it reveals that temperature predicted at joint is $145.047^{\circ} \mathrm{C}$ which is sufficient to soften the $\mathrm{ABS}$ thermoplastic material. The softened thermoplastic flows around the external features of brass insert and improves the performance of joint. This significance is well connected with results described by Roopa Rani at al. [6]. 


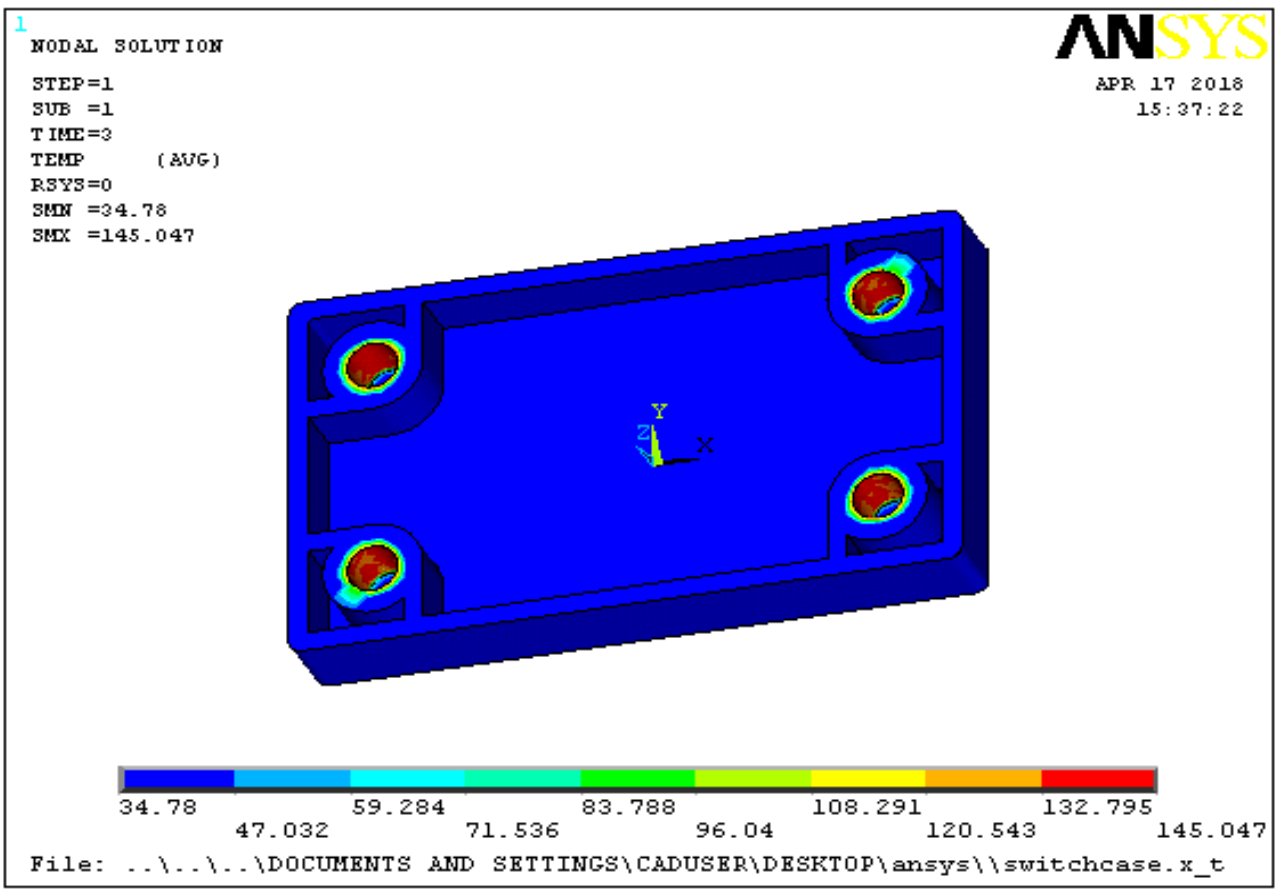

Fig. 21 Temperature distribution at joint interface using optimized slotted horn

\subsection{Experimental validation of simulated results}

The experiments were carried out for validating the performance of slotted block horn design using ultrasonic insertion machine. The slotted block horn was fabricated with optimal design using Aluminium alloy (AA6351) was mounted on the ultrasonic insertion machine and insertion experiments were carried out. Specifications of ultrasonic insertion machine are shown in Table 8. The experimental setup for multiple insertions using slotted block horn is shown in Fig. 22 and Fig. 23 shows the sample of back-end cover of electrical switch box with multiple brass inserts.

Table 8 Specifications of ultrasonic insertion machine

\begin{tabular}{|c|l|l|}
\hline S.No & Description & Value \\
\hline 1 & Make & Johnson Plastosonic Pvt. Ltd, Pune \\
\hline 2 & Input power & $230 \mathrm{~V}, 50 \mathrm{~Hz}$ Single phase \\
\hline 3 & Output power & $1500 \mathrm{~W}$ \\
\hline 4 & Output frequency & $20 \mathrm{kHz}$ \\
\hline 5 & Max. Amplitude & $60 \mathrm{microns}$ \\
\hline 6 & Max. Pressure & $10 \mathrm{bar}$ \\
\hline 7 & Stroke length & $100 \mathrm{~mm}$ \\
\hline
\end{tabular}




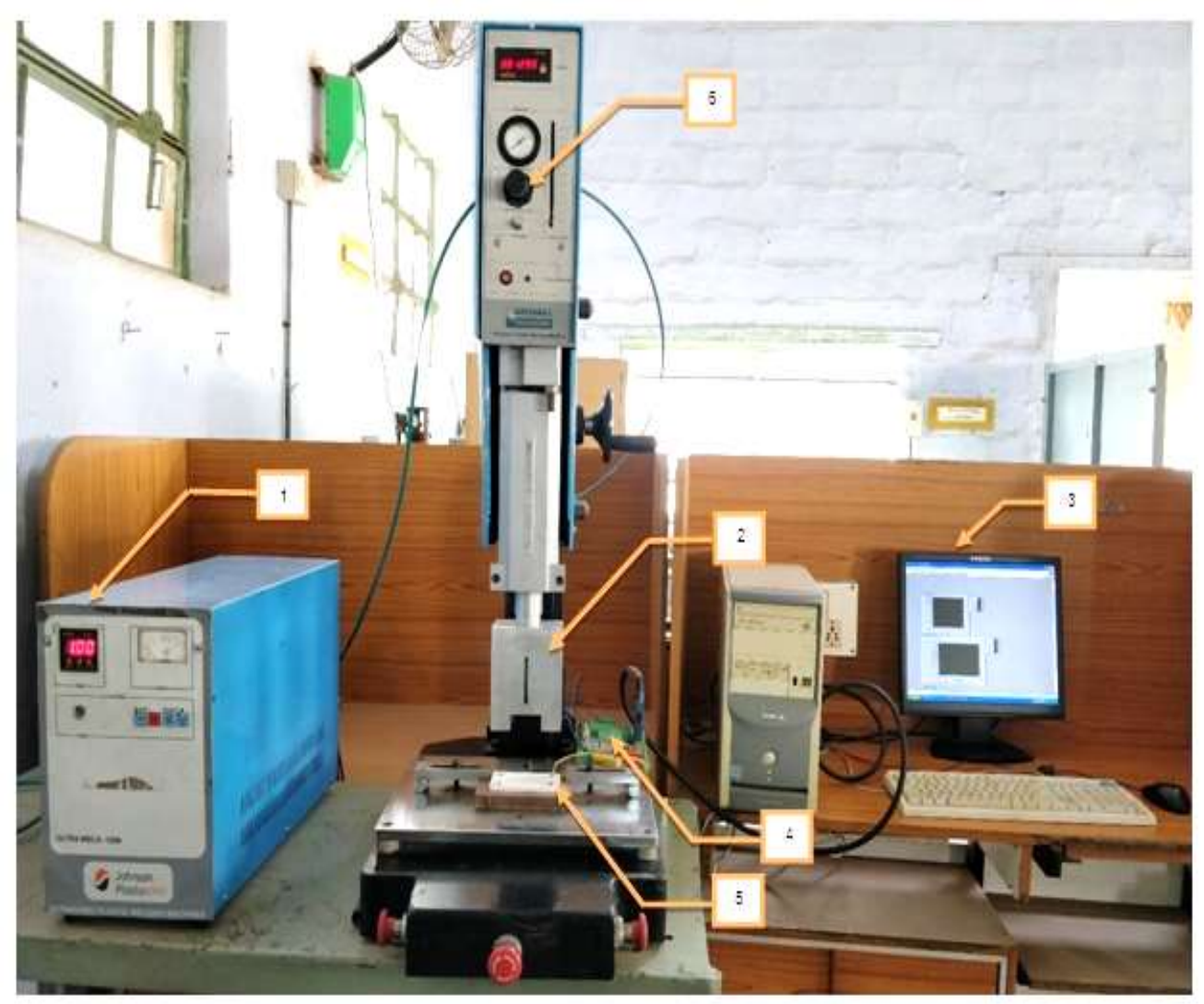

1. Control panel 2. Slotted block horn 3. Console

4. Thermocouple 5. ABS thermoplastic component 6. Pressure regulator

Fig. 22 Experimental set-up for conducting experiments

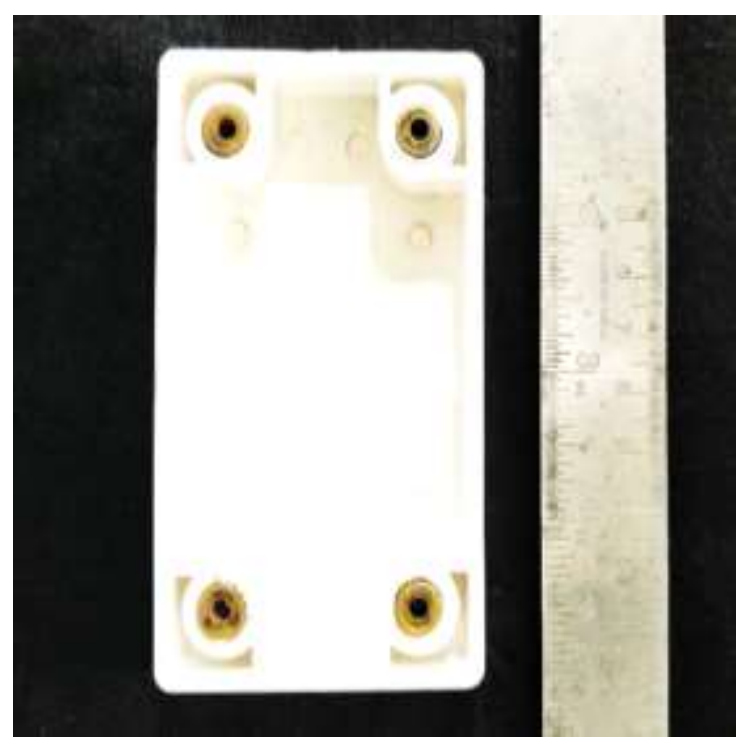

Fig. 23 ABS thermoplastic component with brass inserts after insertion

During insertion, temperature developed at the joint was measured using thermocouple and Data Acquisition System (DAQ). The DAQ includes the following: sensors - ' $k$ ' type thermocouple, terminal blockTBX-68T, National Instruments DAQ card- 4351 and 'Lab View' analyzing software. Fig. 24 shows the block diagram of data acquisition system. 


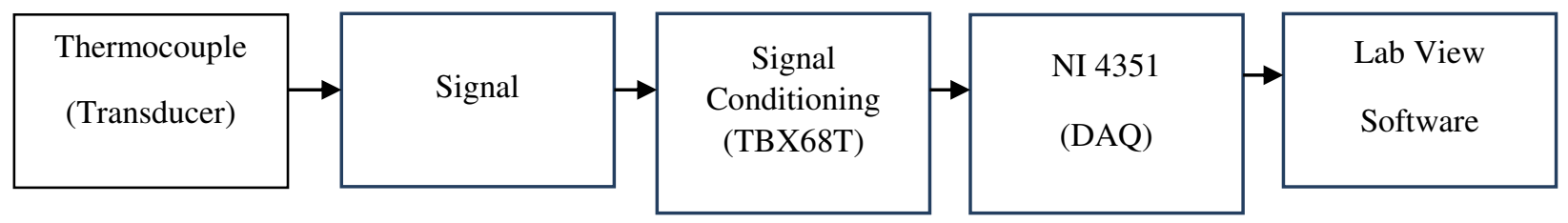

Fig. 24 Block diagram of data acquisition system

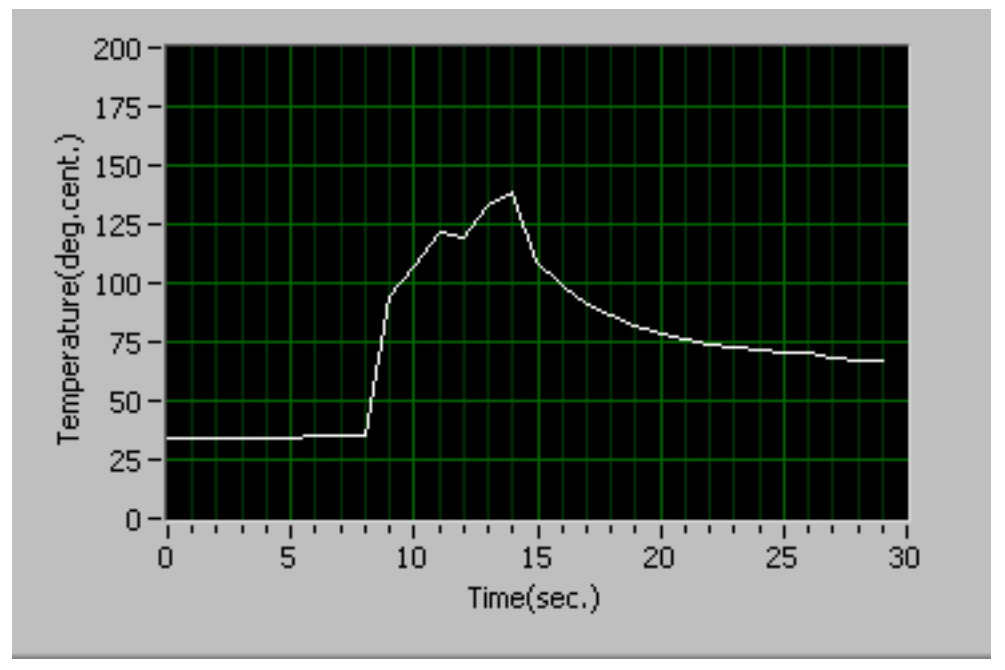

Fig. 25 Temperature at the joint interface for optimized slotted block horn

Fig. 25 shows temperature distribution graph obtained from Lab View program and the maximum temperature observed at joint is $138.65^{\circ} \mathrm{C}$ which is in good agreement with outcome of thermal analysis. This result obtained in this work is well in agreement with Roopa Rani et al. [6]. Horizontal line in the graph indicates room temperature before insertion. When insertion starts, temperature rises to maximum level and gradually decreases with time duration of 8-14 seconds. Time taken to reach maximum temperature at joint is 6 seconds. It is observed that the temperature developed at the joint was above the glass transition temperature of ABS thermoplastic material. The reason is heat developed at the joint is directly proportional to square of the amplitude (Refer. Equation (14)). Since high displacement amplitude is obtained from optimal geometry of slotted block horn, more frictional force is applied over the plastic material at joint. So, the thermoplastic softens and flows around the external features of the insert which may improve the performance ultrasonically fastened joint. Thus, optimum design of slotted block horn for back-end cover of electrical switch box are validated experimentally.

\section{Conclusions}

In this study, slotted block horn is designed for an industrial component then design of horn were optimized using FEA - RSM - GA integration technique. The conclusions drawn from this study are:

1. Block horn should have longitudinal slots to reduce transverse coupling and to improve the uniformity of longitudinal displacement.

2. Slot dimensions, number of slots and location of the slots were decided using modal and harmonic analysis as per the design matrix of response surface methodology. 
3. Non-linear model was developed for improving the displacement amplitude using RSM, then the same was used as fitness function in GA and optimum design of the block horn was obtained.

4. Modal and harmonic analyses were performed for optimal design of slotted block and the results show that optimal design is safe within design parameters and metallurgical limit.

5. Thermal analysis was performed at the joint to validate the optimal design of slotted block horn theoretically.

6. Slotted block horn was fabricated with optimum design using Aluminium alloy (AA 6351) and confirmation experiments were carried out.

7. It was found that the temperature predicted from thermal analysis using FEA correlates well with temperature measured from experiments. This shows that the adopted RSM-FEA-GA integration technique is effective for improving the performance of slotted block horn.

Acknowledgments: The authors express their sincere thanks to the Management and the Principal, PSG College of Technology, Coimbatore for providing the necessary support and infrastructure to carry out this work.

\section{Declarations}

Author contribution: All authors named on the manuscript have made a significant to the writing, concept, execution, or interpretation of the work represented.

Funding: Not Applicable

Availability of data and material: Not Applicable

Code availability: Not Applicable

Conflict of interest: The authors declare no competing interests.

\section{References}

1. Roopa Rani M, Prakasan K, Rudramoorthy R (2015) Studies on High Density Polyethylene in the Far-field Region in Ultrasonic Welding of Plastics. Polymer-Plastics Technology and Engineering 47: 762-770. https://doi.org/10.1080/03602550802188649.

2. Cardoni A, Lucas M (2002) Enhanced vibration performance of ultrasonic block horns. Ultrasonics 40:365-369. https://doi.org/10.1016/S0041-624X (02)00123-3.

3. Graham G, Petzing JN, Lucas M (1999) Modal analysis of ultrasonic block horns by ESPI. Ultrasonics 3:149157. https://doi.org/10.1016/S0041-624X (98)00050-X.

4. Lucas M, Smith AC (1997) Redesign of Ultrasonic Block Horns for Improved Vibration Performance. Journal of Vibration and Acoustics 119:410-414. https://doi.org/10.1115/1.2889739.

5. Sun-Rak Kim, Jae-Hak Lee, Choong D Yoo, Jun-Yeob Song, Seung S Lee (2011) Design of highly uniform spool and bar horns for ultrasonic bonding. IEEE Transactions on Ultrasonics, Ferroelectrics, and Frequency Control 58:2194-2201. https://doi.org/10.1109/TUFFC.2011.2069. 
6. Roopa Rani M, Rudramoorthy R (2013) Computational modeling and experimental studies of the dynamic performance of ultrasonic horn profiles used in plastic welding. Ultrasonics 53: 763-772. https://doi.org/10.1016/j.ultras.2012.11.003.

7. Roopa Rani M, Prakasan K, Rudramoorthy R (2015) Studies on thermo-elastic heating of horns used in ultrasonic plastic welding. Ultrasonics 55:123-132. https://doi.org/10.1016/j.ultras.2014.07.005.

8. Dipin Kumar R, Roopa Rani M, Elangovan S (2014) Design and Analysis of Slotted Horn for Ultrasonic Plastic Welding. $\quad$ Applied Mechanics and $\quad$ Materials https://doi.org/10.4028/www.scientific.net/AMM.

9. Guangchao Han, Kai Li, Zhuo Peng, Junsong Jin, Ming Sun, Xinyun Wang (2017) A new porous block sonotrode for ultrasonic assisted micro plastic forming. International Journal of Advanced Manufacturing Technology 89:2193-2202. https:// DOI 10.1007/s00170-016-9179-y.

10. S Kumar, W Ding, Z Sun, C S Wu (2018) Analysis of the dynamic performance of a complex ultrasonic horn for application in friction stir welding. International Journal of Advanced Manufacturing Technology 97:1269 1284. https://doi.org/10.1007/s00170-018-2003-0.

11. Shimaalsadat Mostafavi, Daniel Frank Hesser, Bernd Markert (2018) Effect of process parameters on the interface temperature in ultrasonic aluminum wire bonding. Journal of Manufacturing Processes36: 104-114. https://doi.org/10.1016/j.jmapro.2018.09.020.

12. Li, H, Cao, B, Yang, JW, Liu J (2018) Modeling of resistance heat assisted ultrasonic welding of Cu-Al joint. Journal of materials processing technology 256: 121-130. https://doi.org/10.1016/j.jmatprotec.2018.02.008.

13. Shuyu Lin, Hao Gu, Jie Xu (2018) Actively adjustable step-type ultrasonic horns in longitudinal vibration Journal of Sound and Vibration 419: 367-379. https://doi.org/10.1016/j.jsv.2018.01.033.

14. Dongkyun Lee, Wayne Cai (2017) The effect of horn knurl geometry on battery tab ultrasonic welding quality: 2D finite element simulations. Journal of Manufacturing Processes 28: 428-441. http://dx.doi.org/10.1016/j.jmapro.2017.04.009.

15. Muhammad Bilal Shahid, Jae-Yeon Jung, Dong-Sam Park (2020) Finite element analysis coupled artificial neural network approach to design the longitudinal-torsional mode ultrasonic welding horn. International Journal of Advanced Manufacturing Technology 107:2731-2743. https://doi.org/10.1007/s00170-020-05200-5.

16. Ziad Shakeeb Al Sarraf, Majid Midhat Saeed (2019) Design and analysis of slotted block horn used for ultrasonic power applications. Journal of southwest jiaotong university 54:1-10. https://doi.org/10.35741/issn.0258-2724.54.5.28.

17. Elangovan S, Anand K, Prakasan K (2012) Parametric optimization of ultrasonic metal welding using response surface methodology and genetic algorithm. International Journal of Advanced Manufacturing Technology 63: 561-572. https:// DOI 10.1007/s00170-012-3920-y.

18. Elangovan Sooriyamoorthy, Shenton Ponnayya John Henry, Prakasan Kalakkath (2011) Experimental studies on optimization of process parameters and finite element analysis of temperature and stress distribution on 
joining of $\mathrm{Al}-\mathrm{Al}$ and $\mathrm{Al}-\mathrm{Al} 2 \mathrm{O} 3$ using ultrasonic welding. International Journal of Advanced Manufacturing Technology 55:631-640. https:// DOI 10.1007/s00170-010-3059-7.

19. Chuah, YK, Chien Chang BC, Liu (2000) Effects of the shape of the energy director on far field ultrasonic welding of thermoplastics. Polymer Engineering and Science 40: 157-167. https://doi.org/10.1002/pen.11149.

20. J. Michael Troughton (2008) Handbook of Plastics Joining A Practical Guide. PDI publications, New York. 
Figures

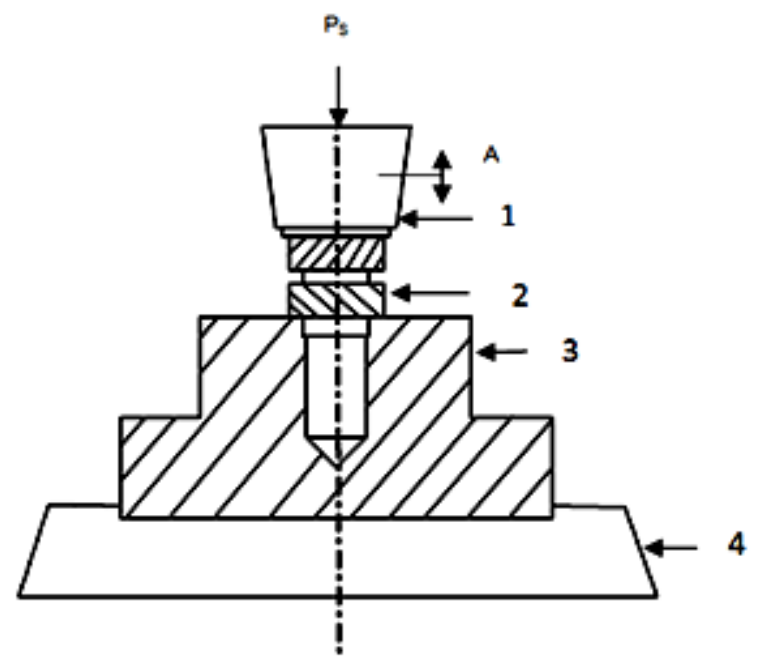

Figure 1

1. Ultrasonic horn 2. Metal insert 3. Thermoplastic part 4. Anvil A - Amplitude of horn vibrations PS Static pressure force Schematic representation of ultrasonic insertion process 


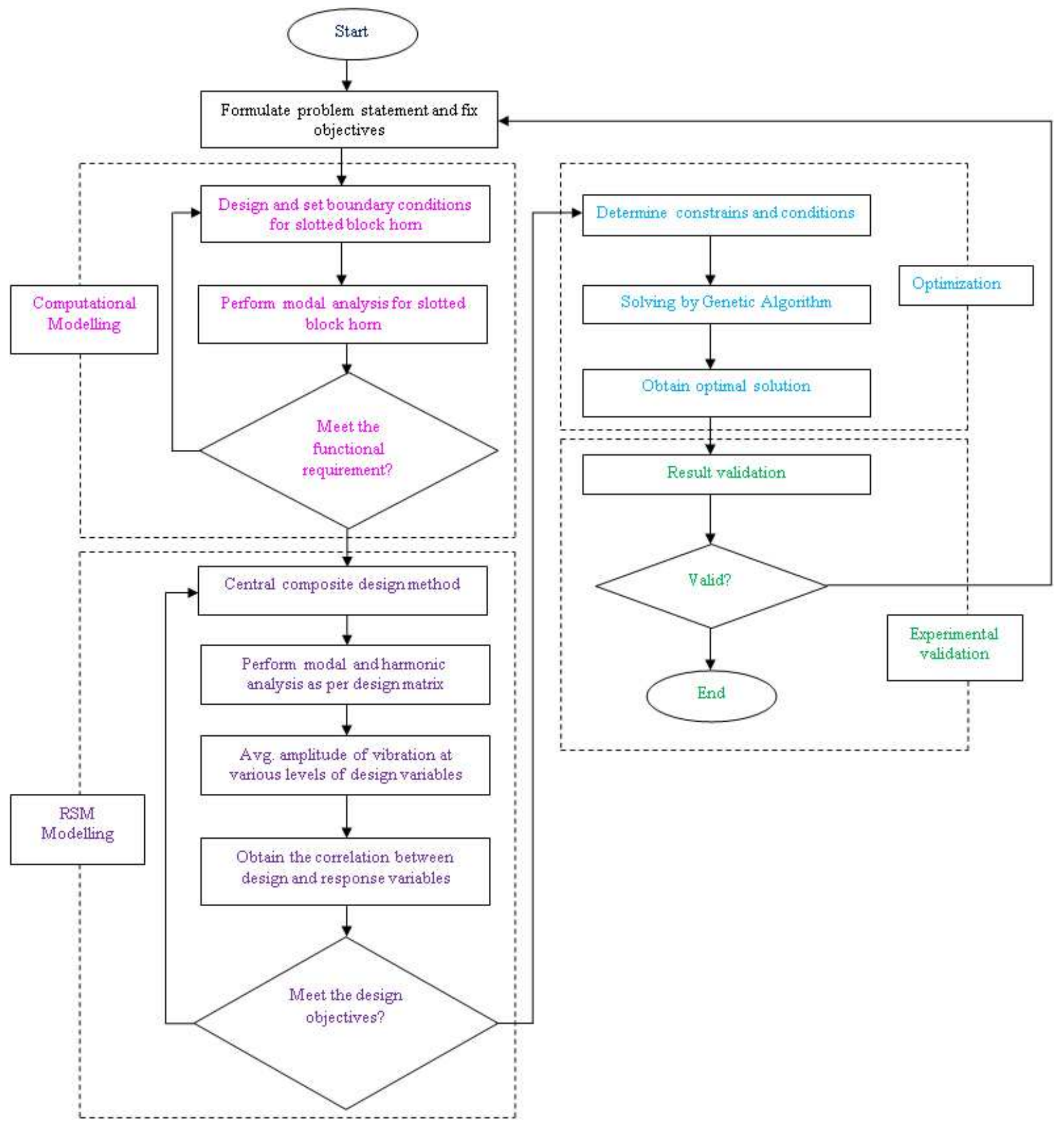

Figure 2

Methodology for design and optimization of slotted block horn 


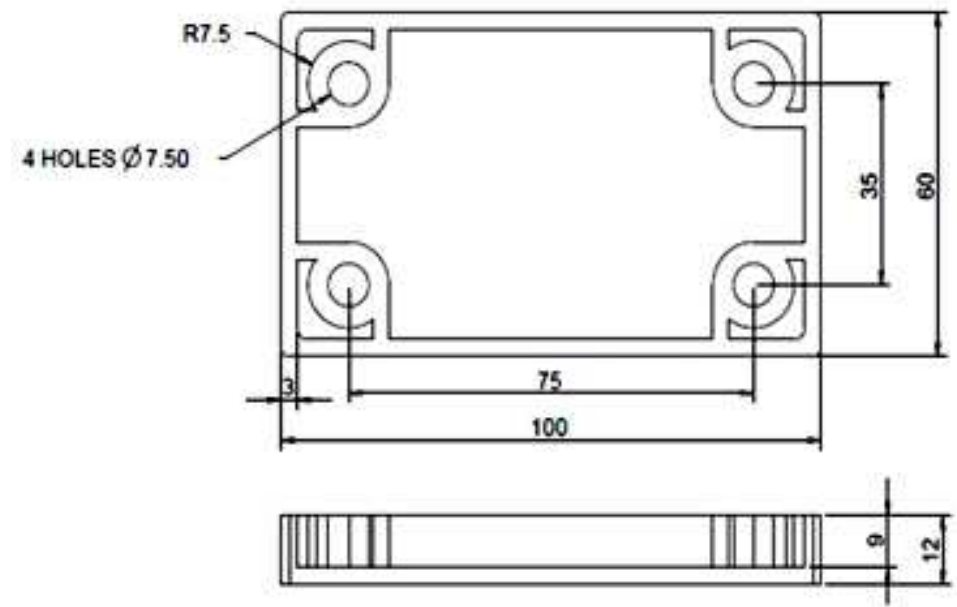

Figure 3

Back-end cover of the electrical switch box with dimensions

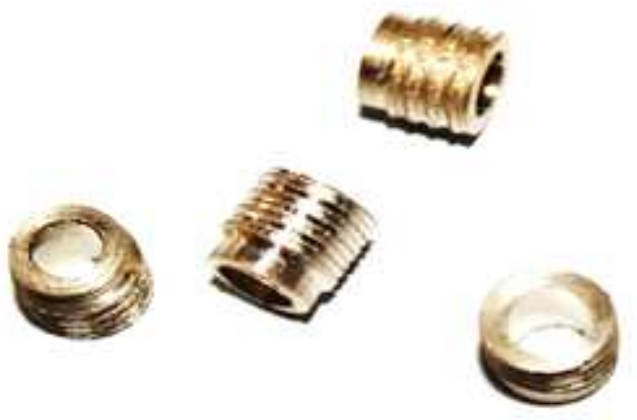

Figure 4

Standard brass inserts for multiple insertions

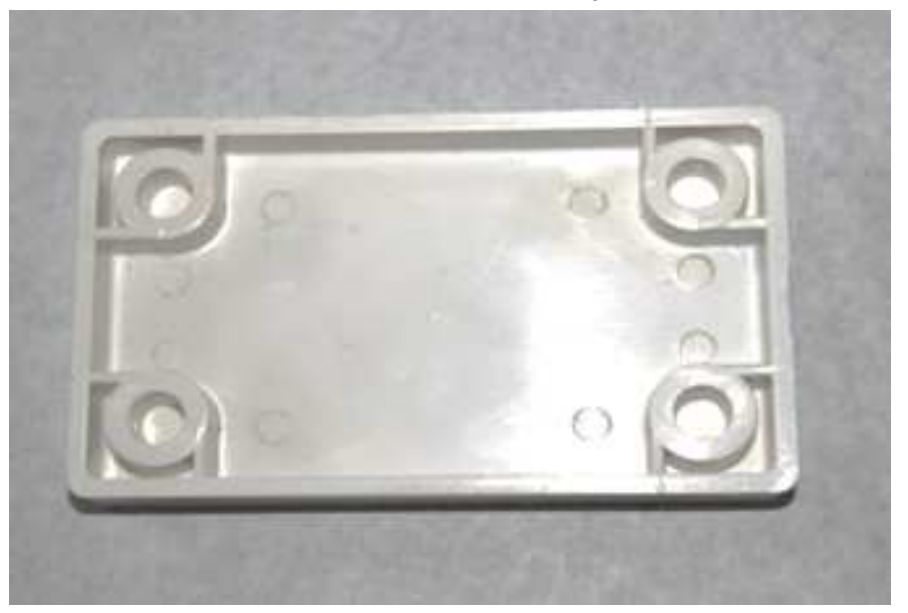

Figure 5 
Fabricated back end cover of eletrical switch box

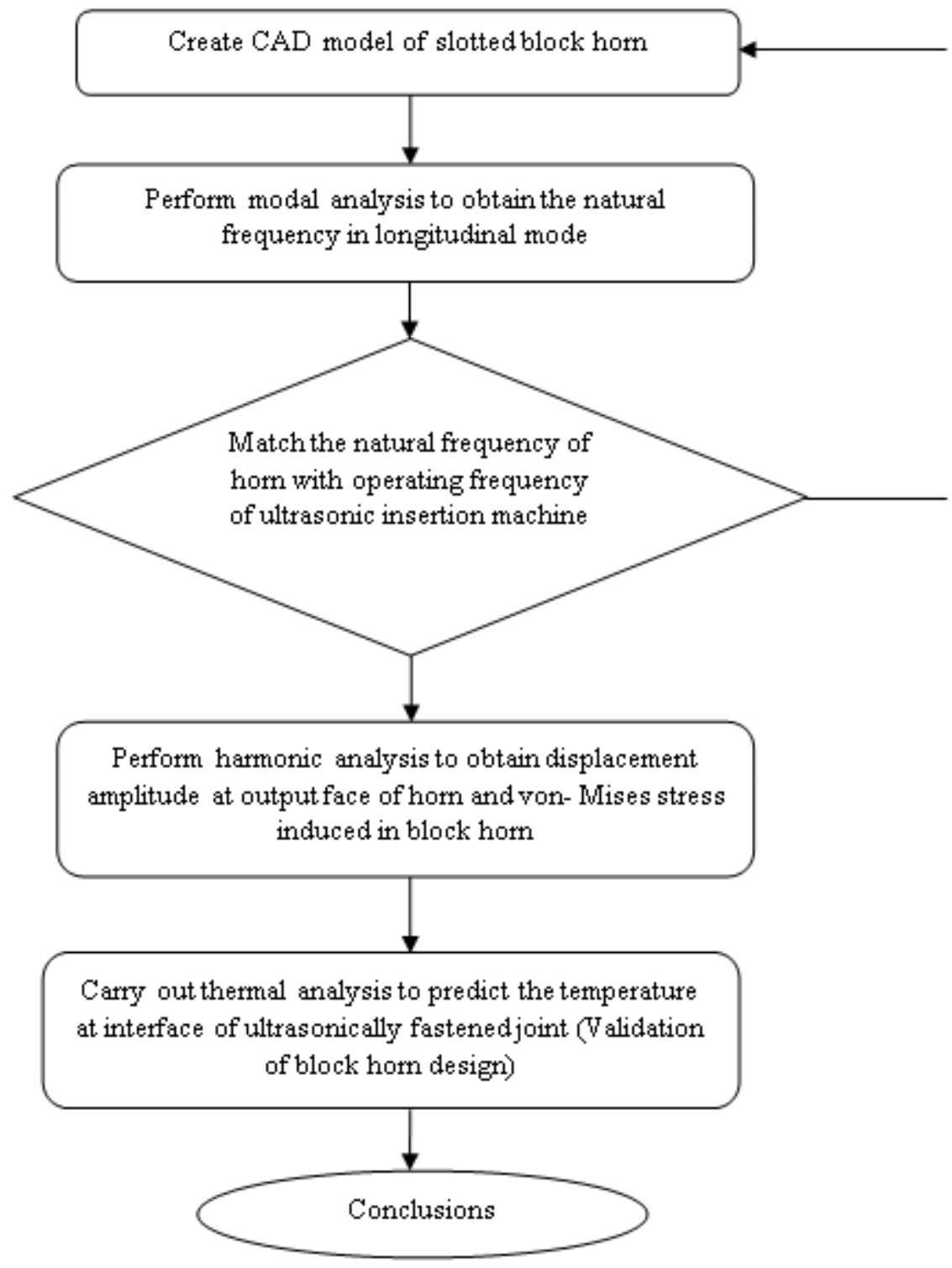

Figure 6

Methodology adopted for computational modelling of block horn 


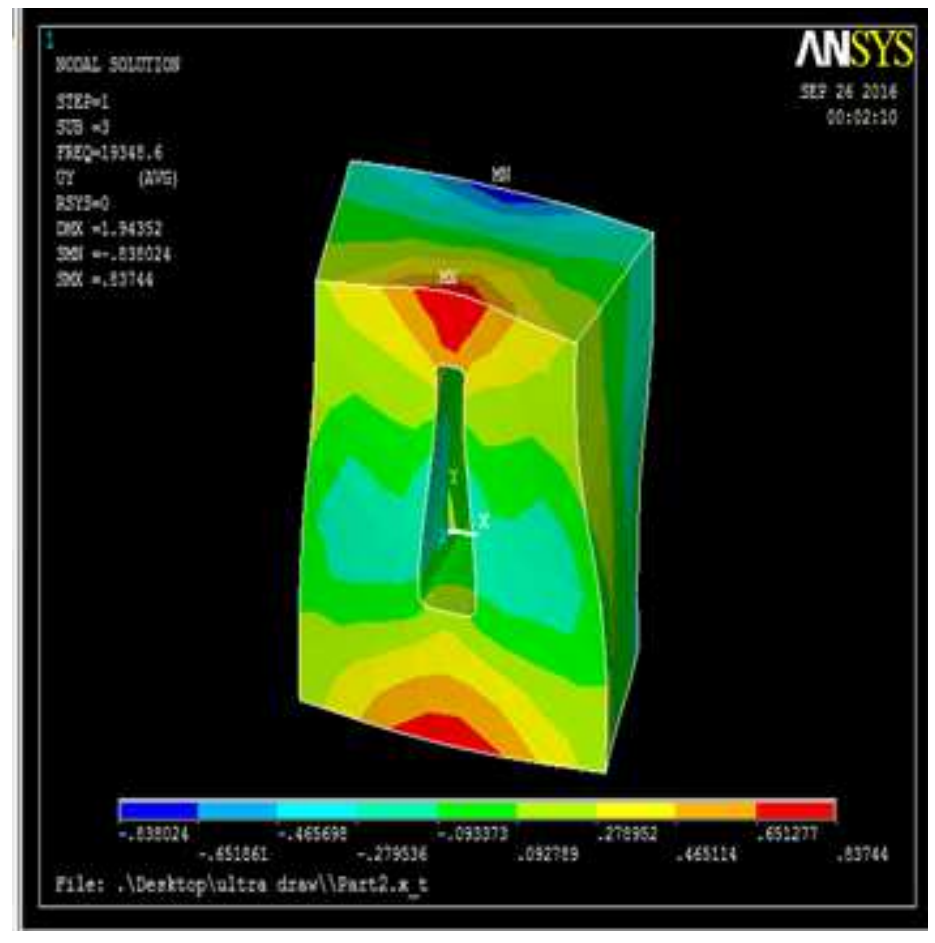

Figure 7

Modal analysis of horn with vertical slot

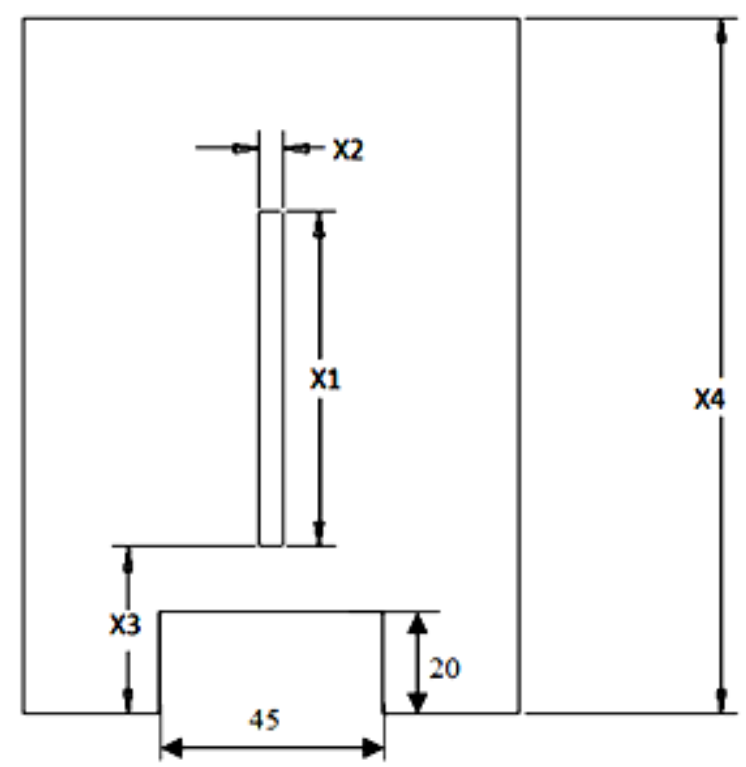

Figure 8

Dimensions of slotted block horn 


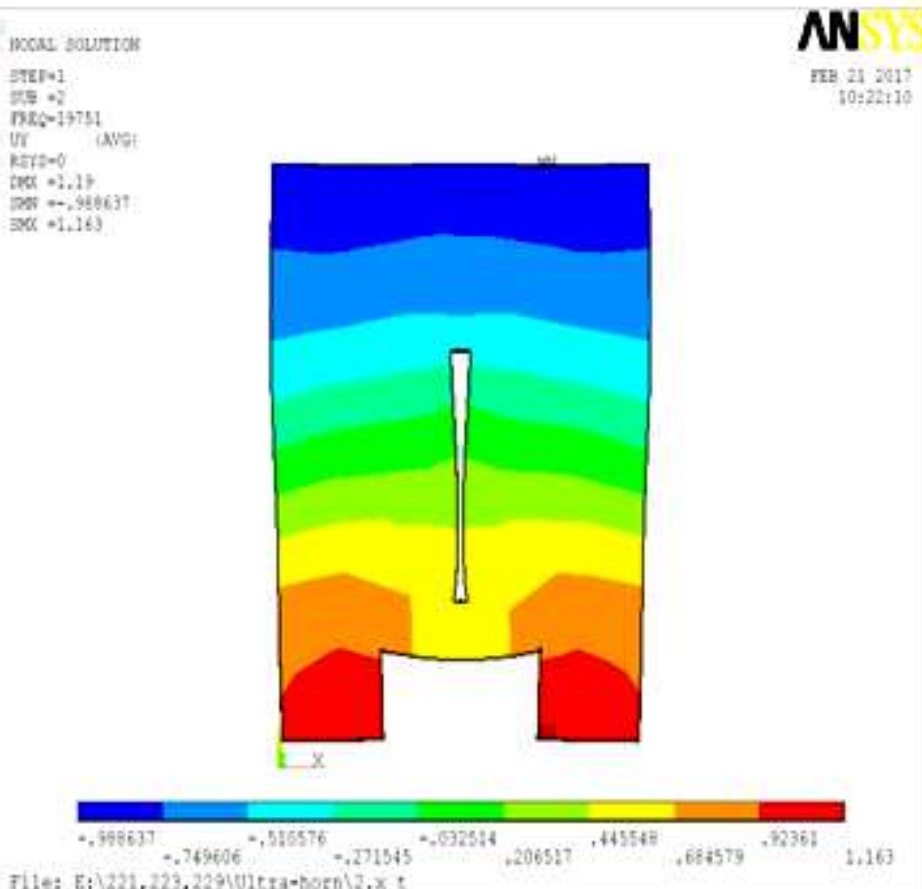

\section{Figure 9}

Modal analysis for 2 nd combination of design variables

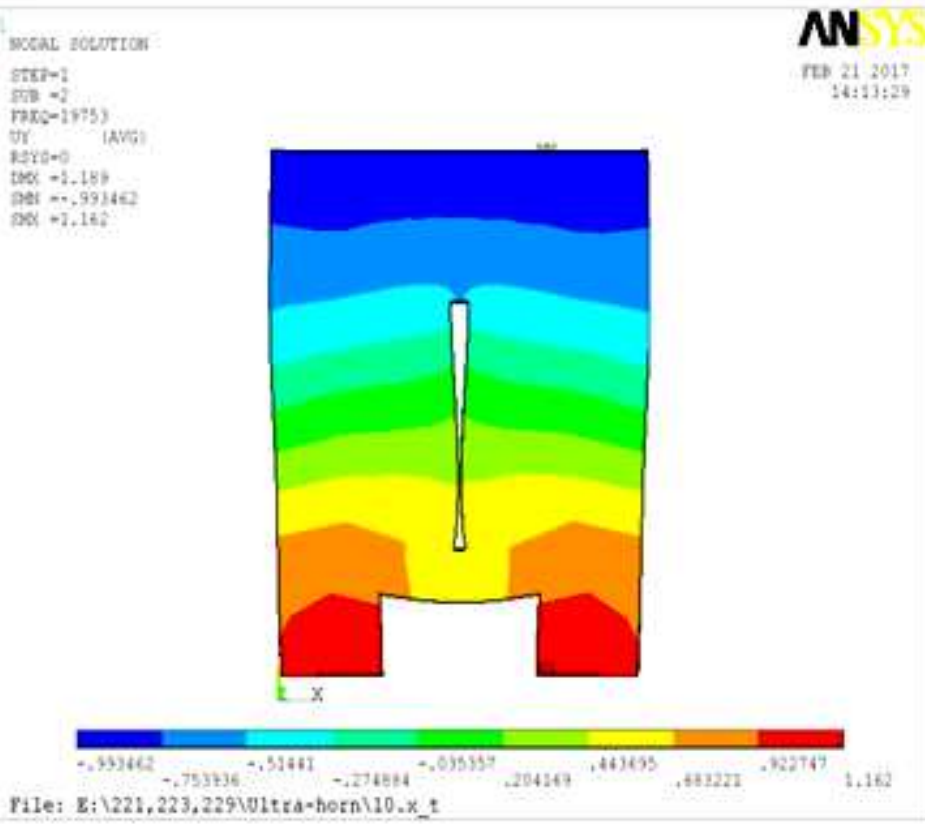

Figure 10

Modal analysis for 10 th combination of design variables 


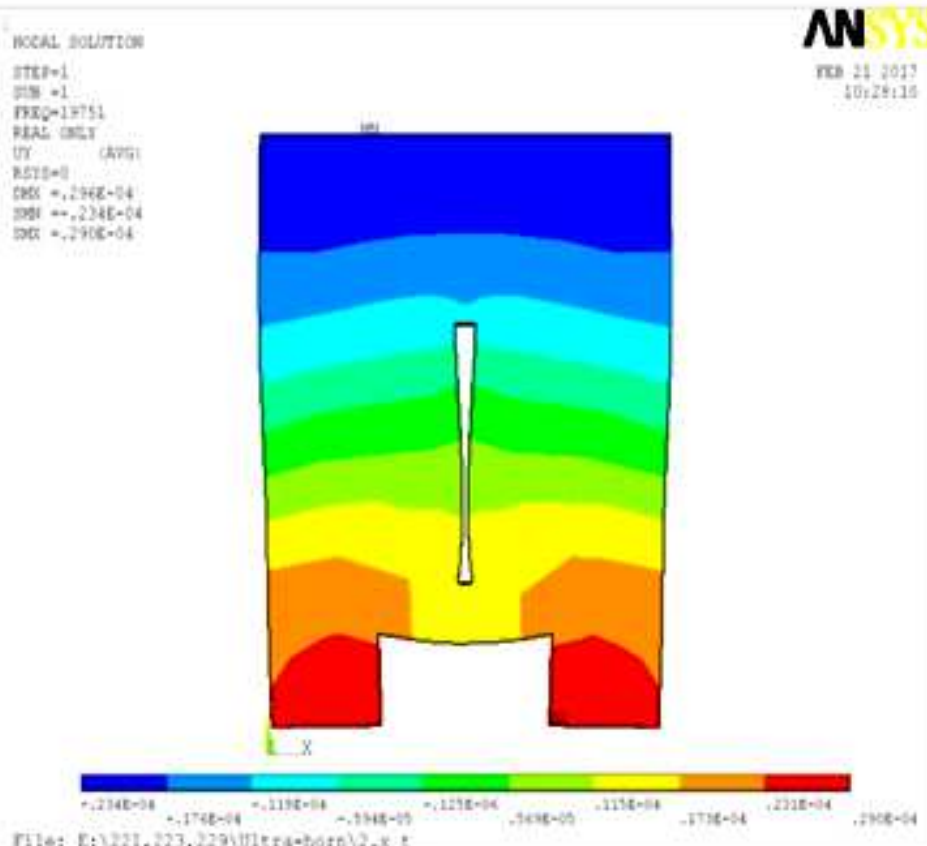

\section{Figure 11}

Displacement amplitude for 2nd combination of design variables

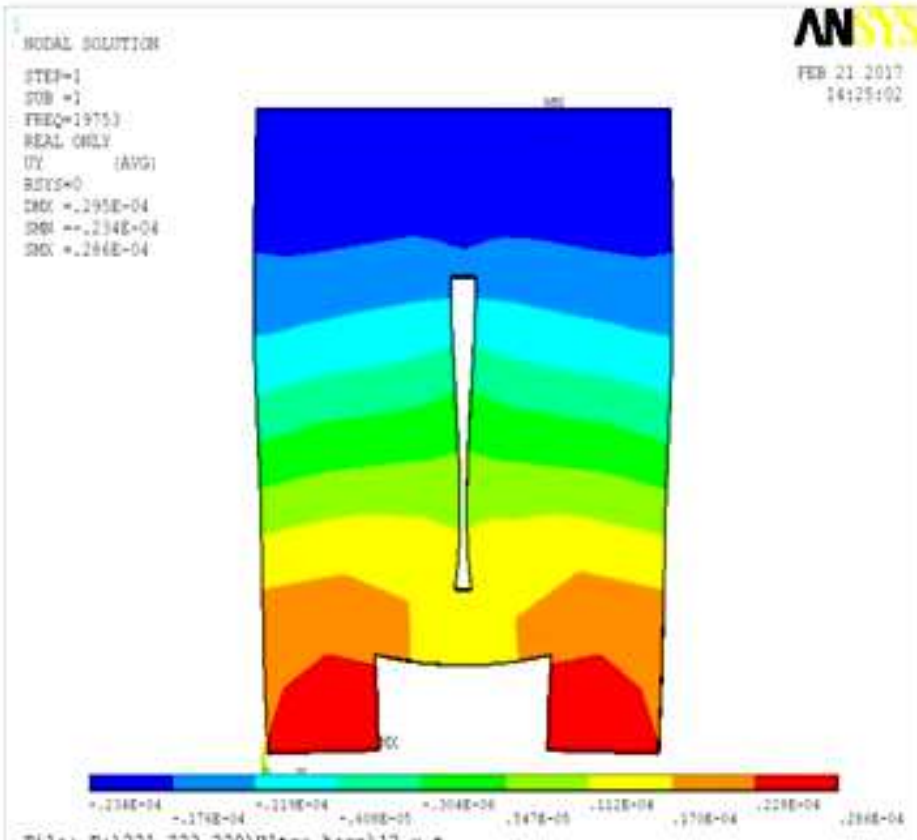

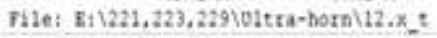

Figure 12

Displacement amplitude for 10th combination of design variables 


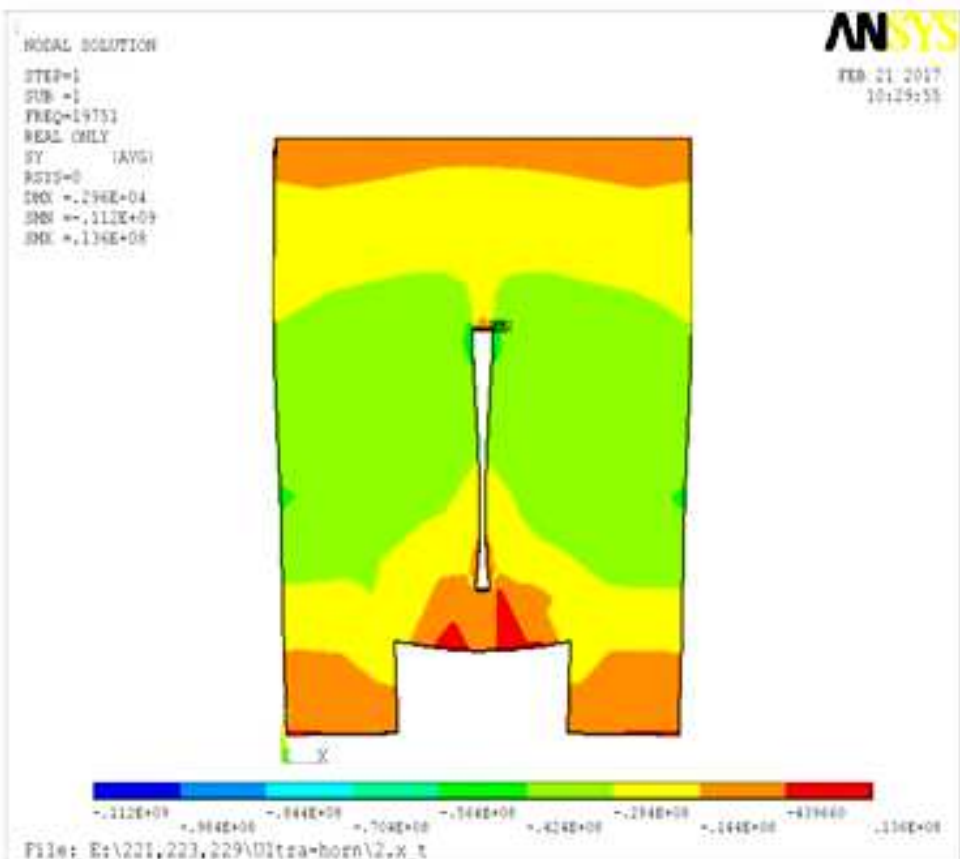

\section{Figure 13}

von-Mises stress induced in block for 2 nd combination of design variables

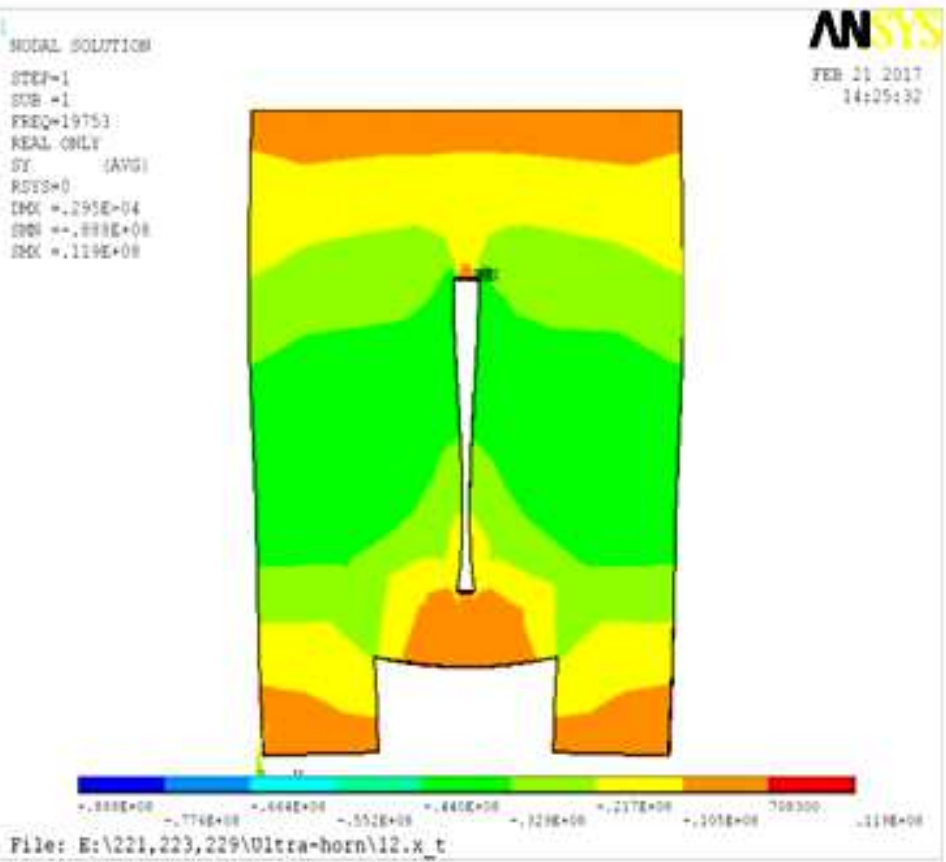

Figure 14

von-Mises stress induced in block for 10th combination of design variables 


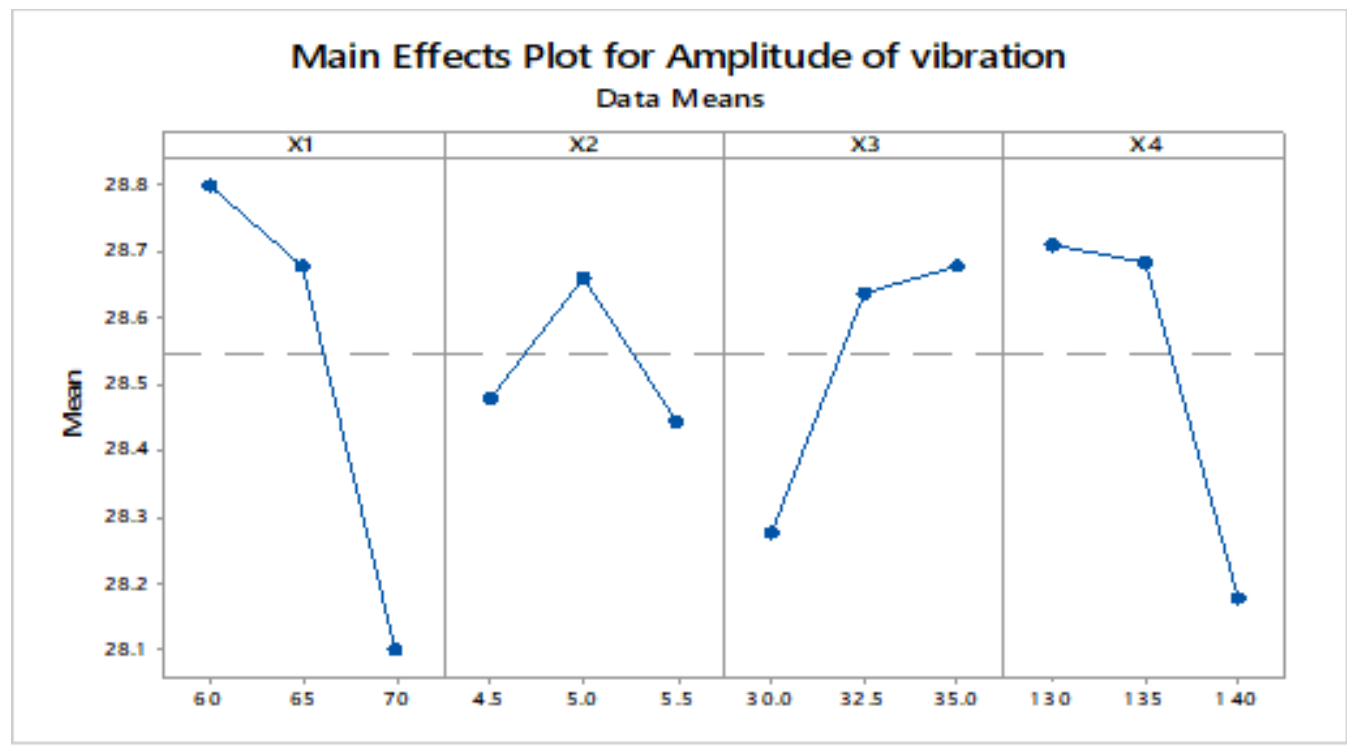

Figure 15

Mean values of amplitude of vibration at various levels of design variables

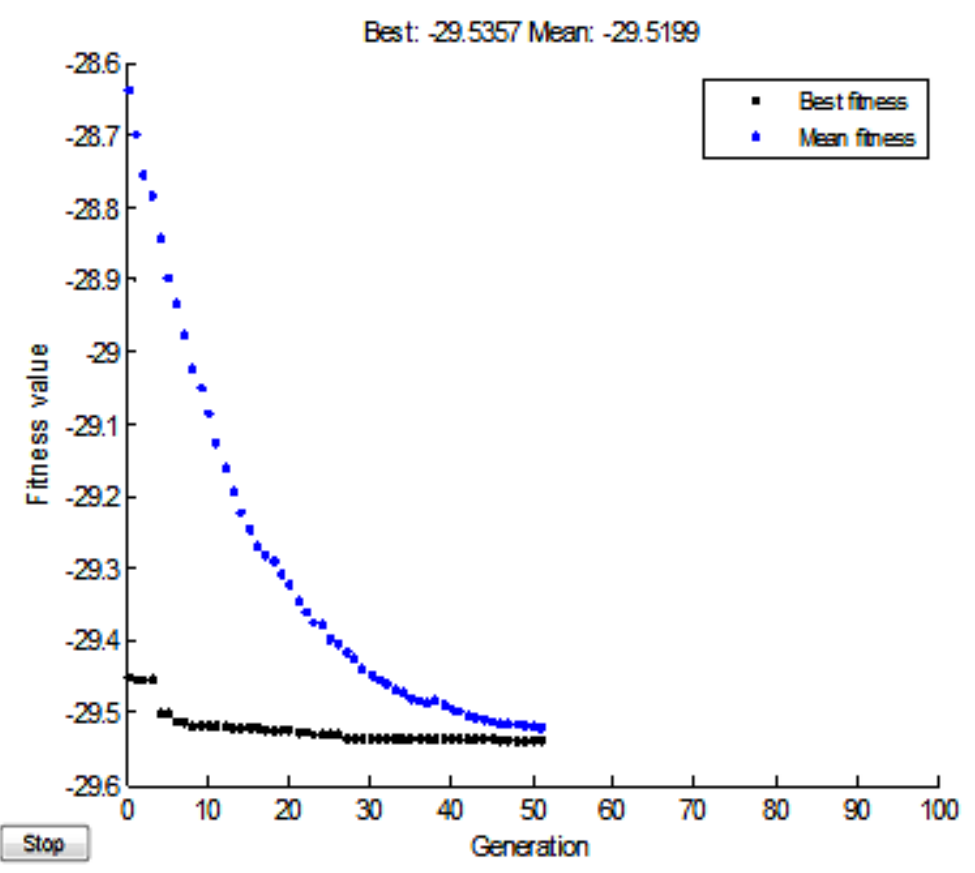

Figure 16

Convergence of fitness value 


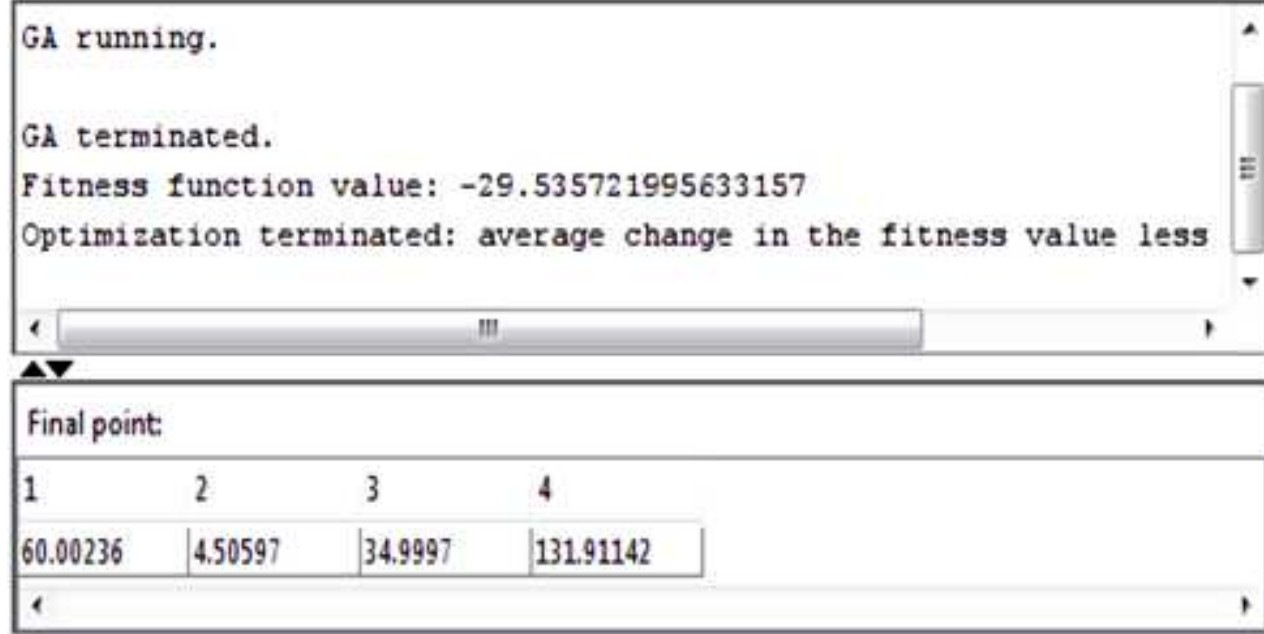

\section{Figure 17}

Converged values of design variables
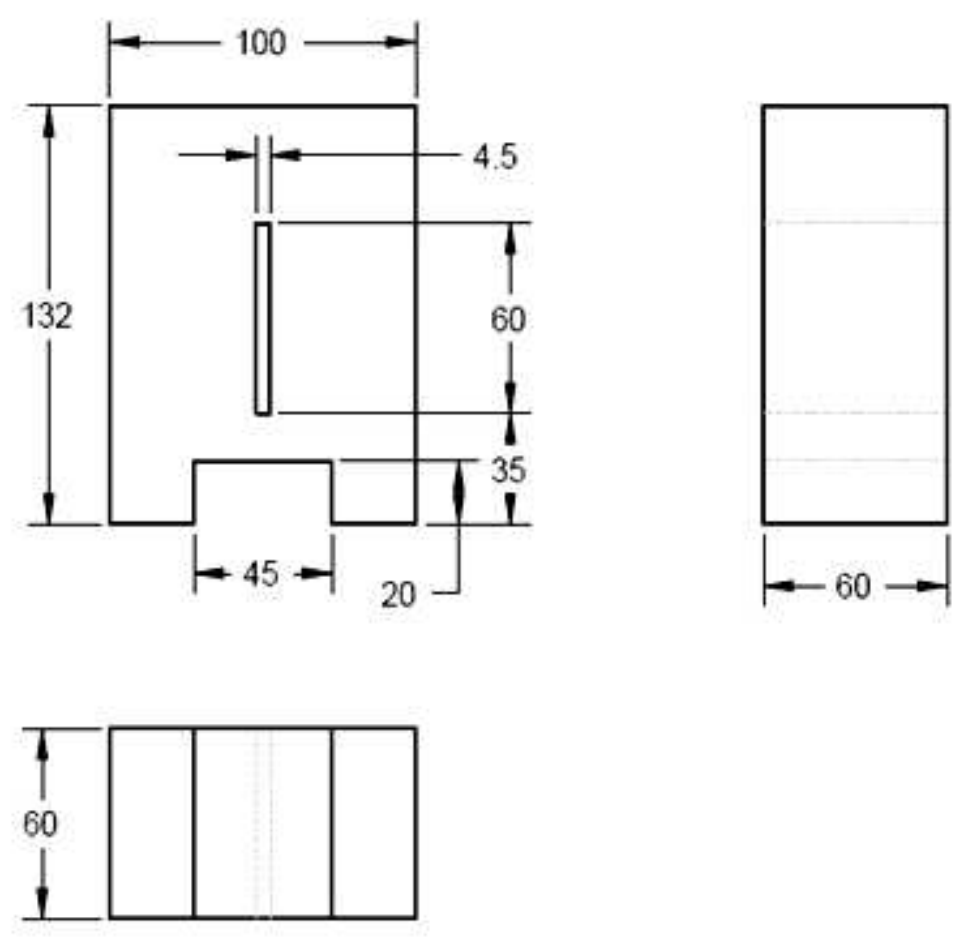

Figure 18

Optimum design of slotted block horn 


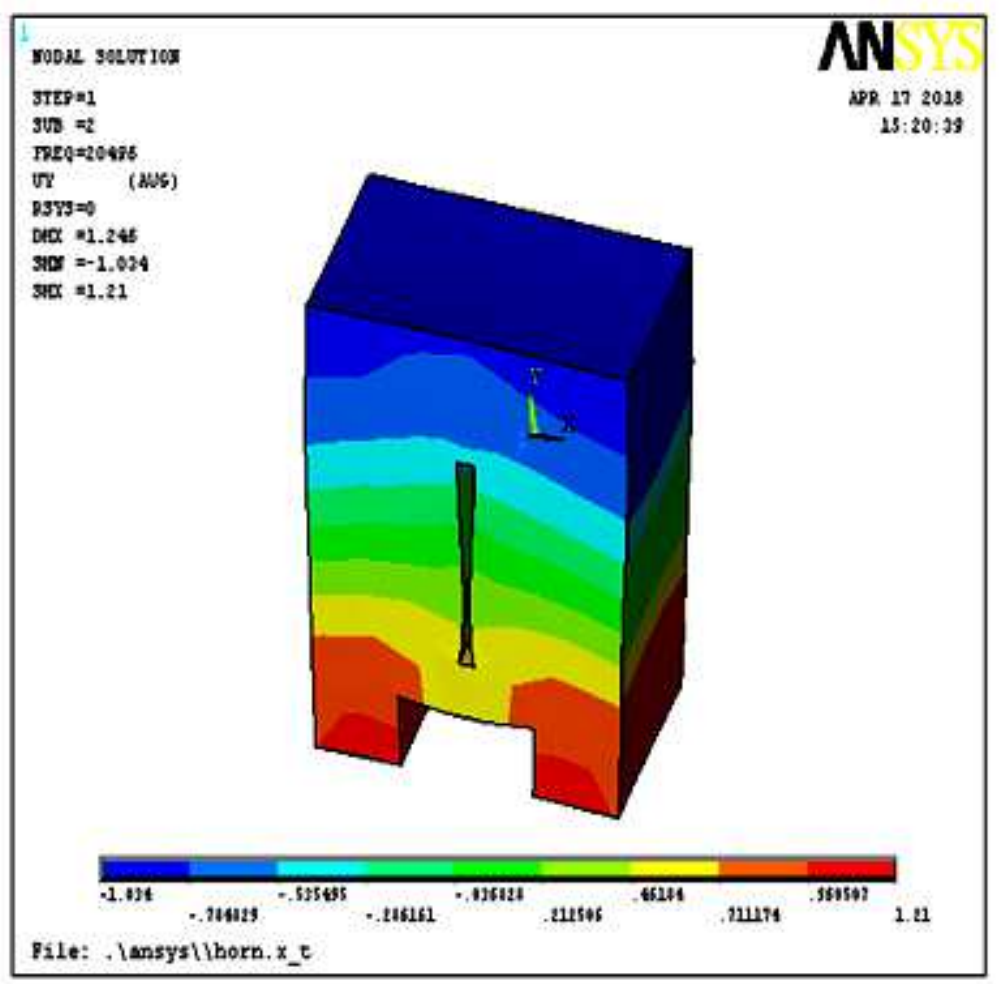

\section{Figure 19}

Modal analysis for optimum design of slotted block horn

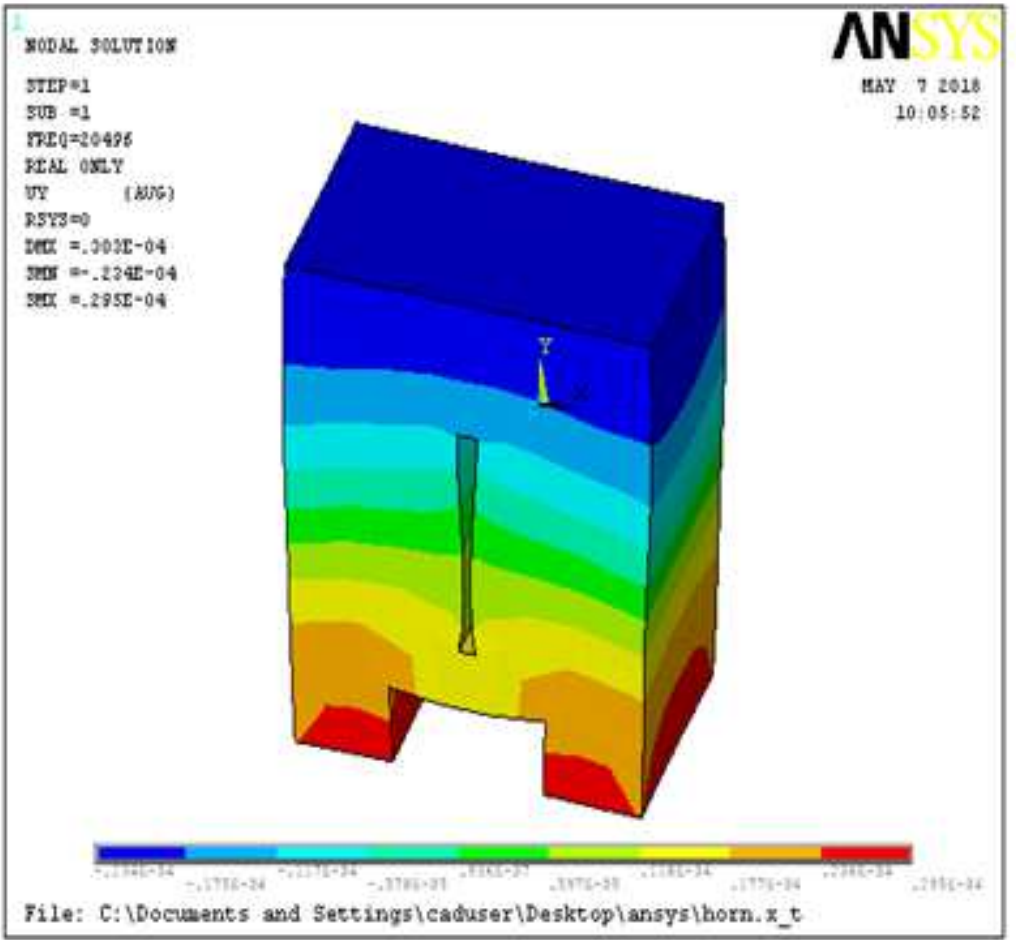

Figure 20

Harmonic analysis for optimum design of slotted block horn 


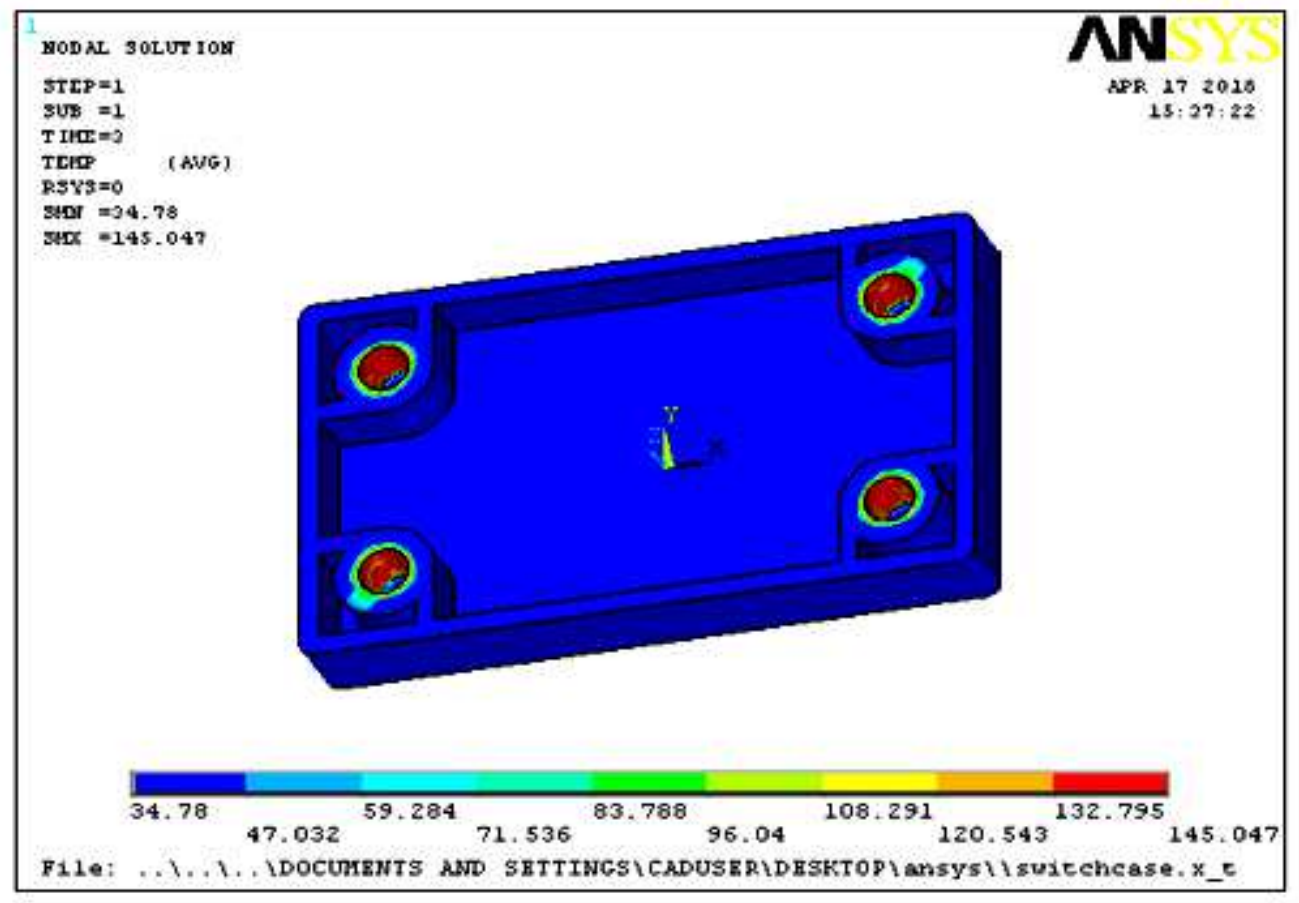

Figure 21

Temperature distribution at joint interface using optimized slotted horn

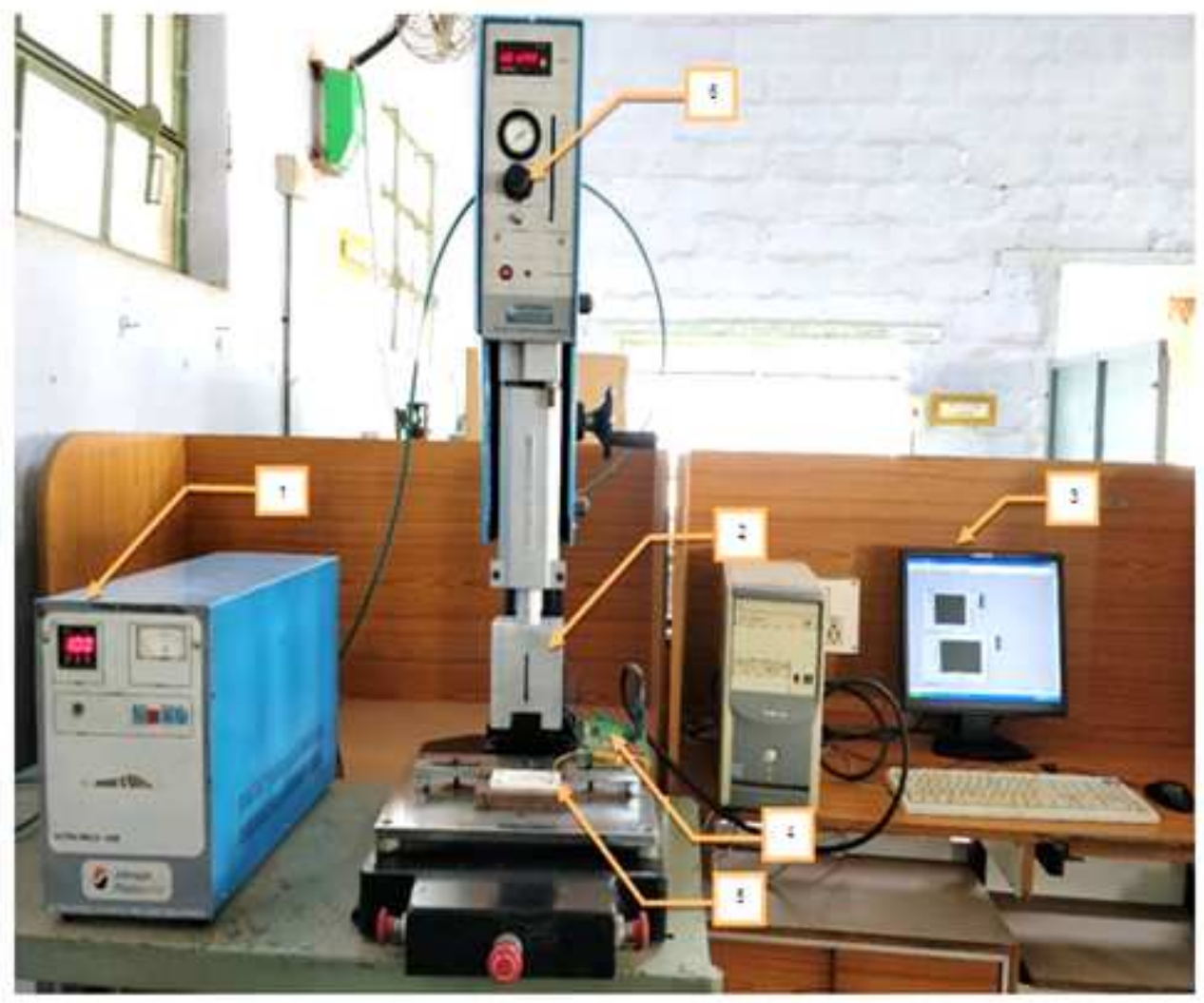

Figure 22 
1. Control panel 2. Slotted block horn 3. Console 4. Thermocouple 5. ABS thermoplastic component 6. Pressure regulator Experimental set-up for conducting experiments

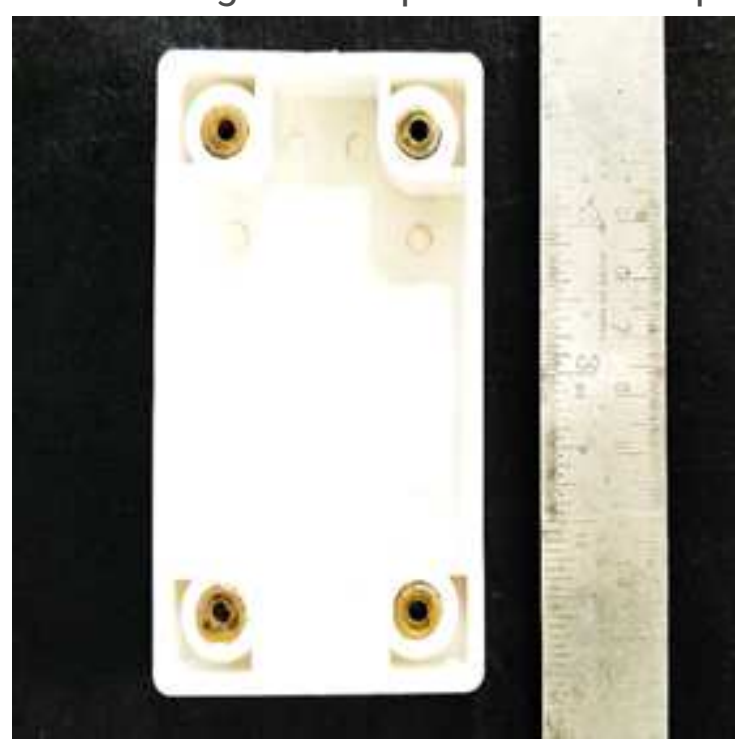

Figure 23

ABS thermoplastic component with brass inserts after insertion

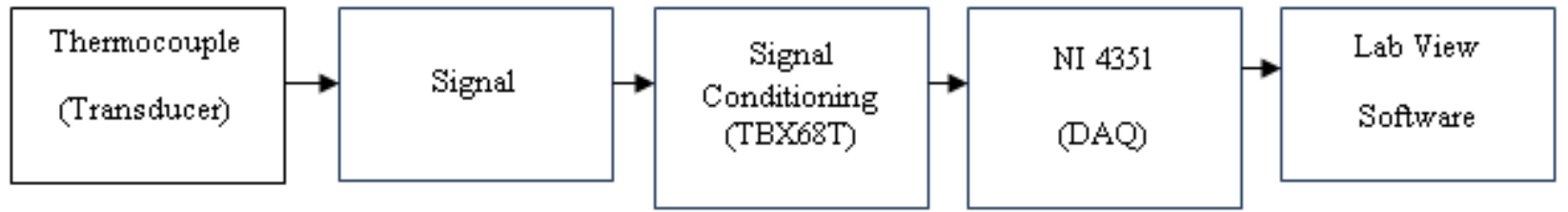

\section{Figure 24}

Block diagram of data acquisition system

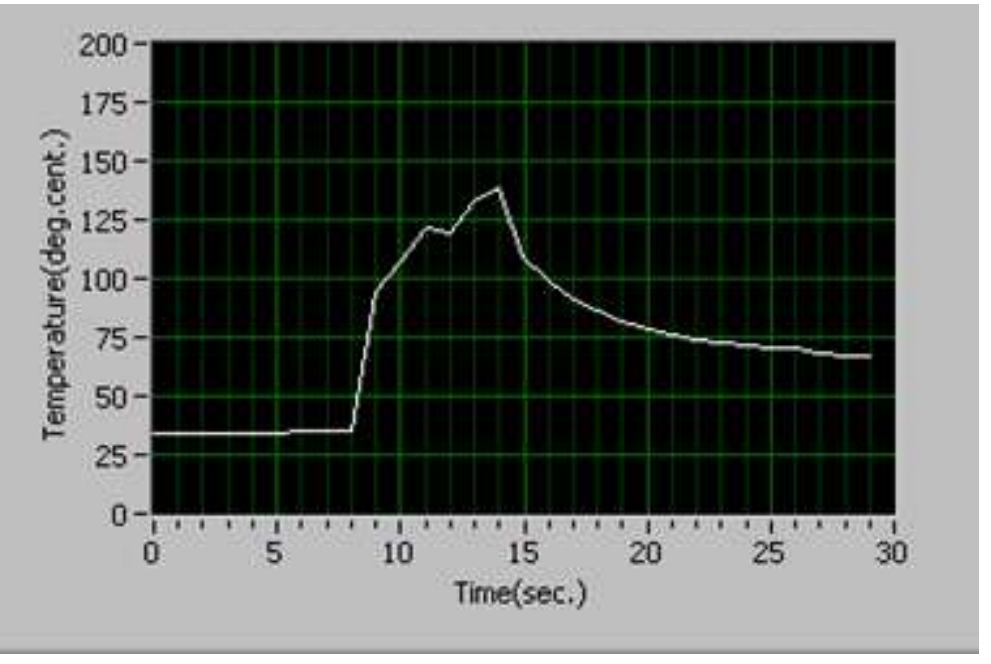

Figure 25

Temperature at the joint interface for optimized slotted block horn 